\title{
Parameterization of oceanic whitecap fraction based on satellite observations
}

\author{
Monique F. M. A. Albert ${ }^{1}$, Magdalena D. Anguelova ${ }^{2}$, Astrid M. M. Manders ${ }^{1}$, Martijn Schaap ${ }^{1}$, and \\ Gerrit de Leeuw ${ }^{1,3,4}$ \\ ${ }^{1}$ TNO, P.O. Box 80015, 3508 TA Utrecht, the Netherlands \\ ${ }^{2}$ Remote Sensing Division, Naval Research Laboratory, Washington, DC 20375, USA \\ ${ }^{3}$ Climate Research Unit, Finnish Meteorological Institute, Helsinki, Finland \\ ${ }^{4}$ Department of Physics, University of Helsinki, Helsinki, Finland \\ Correspondence to: Magdalena D. Anguelova (maggie.anguelova@nrl.navy.mil)
}

Received: 30 May 2015 - Published in Atmos. Chem. Phys. Discuss.: 6 August 2015

Revised: 5 September 2016 - Accepted: 19 September 2016 - Published: 7 November 2016

\begin{abstract}
In this study, the utility of satellite-based whitecap fraction $(W)$ data for the prediction of sea spray aerosol (SSA) emission rates is explored. More specifically, the study aims at evaluating how an account for natural variability of whitecaps in the $W$ parameterization would affect SSA mass flux predictions when using a sea spray source function (SSSF) based on the discrete whitecap method. The starting point is a data set containing $W$ data for 2006 together with matching wind speed $U_{10}$ and sea surface temperature (SST) $T$. Whitecap fraction $W$ was estimated from observations of the ocean surface brightness temperature $T_{\mathrm{B}}$ by satellite-borne radiometers at two frequencies (10 and $37 \mathrm{GHz}$ ). A global-scale assessment of the data set yielded approximately quadratic correlation between $W$ and $U_{10}$. A new global $W\left(U_{10}\right)$ parameterization was developed and used to evaluate an intrinsic correlation between $W$ and $U_{10}$ that could have been introduced while estimating $W$ from $T_{\mathrm{B}}$. A regional-scale analysis over different seasons indicated significant differences of the coefficients of regional $W\left(U_{10}\right)$ relationships. The effect of SST on $W$ is explicitly accounted for in a new $W\left(U_{10}, T\right)$ parameterization. The analysis of $W$ values obtained with the new $W\left(U_{10}\right)$ and $W\left(U_{10}, T\right)$ parameterizations indicates that the influence of secondary factors on $W$ is for the largest part embedded in the exponent of the wind speed dependence. In addition, the $W\left(U_{10}, T\right)$ parameterization is able to partially model the spread (or variability) of the satellite-based $W$ data. The satellite-based parameterization $W\left(U_{10}, T\right)$ was applied in an SSSF to estimate the global SSA emission rate. The thus obtained SSA pro-
\end{abstract}

duction rate for 2006 of $4.4 \times 10^{12} \mathrm{~kg} \mathrm{year}^{-1}$ is within previously reported estimates, however with distinctly different spatial distribution.

\section{Introduction}

Whitecaps are the surface phenomenon of bubbles near the ocean surface. They form at wind speeds of around $3 \mathrm{~m} \mathrm{~s}^{-1}$ and higher, when waves break and entrain air in the water which subsequently breaks up into bubbles which rise to the surface (Thorpe, 1982; Monahan and O'Muircheartaigh, 1986). The estimated annual global average of whitecap cover, i.e., the fraction of the ocean surface covered with whitecaps $W$, is $3.4 \%$ (Blanchard, 1963). Being visibly distinguishable from the rough sea surface, whitecaps are the most direct way to parameterize the enhancement of many air-sea exchange processes including gas and heat transfer (Andreas, 1992; Fairall et al., 1994; Woolf, 1997; Wanninkhof et al., 2009), wave energy dissipation (Melville, 1996; Hanson and Phillips, 1999), and the production rate of sea spray aerosols (SSAs) (e.g., Blanchard, 1963, 1983; Monahan et al., 1983; O’Dowd and de Leeuw, 2007; de Leeuw et al., 2011), because all these processes involve wave breaking and bubbles.

Measurements of the whitecap fraction $W$ are usually extracted from photographs and video images collected from ships, towers, and air planes (Monahan, 1971; Asher and Wanninkhof, 1998; Callaghan and White, 2009; Kleiss and 
Melville, 2011). Whitecap fraction is commonly parameterized in terms of wind speed at a reference height of $10 \mathrm{~m}$, $U_{10}$. Wind speed is the primary driving force for the formation and variability of $W$ (Monahan and O'Muircheartaigh, 1986; Salisbury et al., 2013, hereafter SAL13). Whitecap fractions predicted with conventional $W\left(U_{10}\right)$ parameterizations show a large spread between reported $W$ values (Lewis and Schwartz, 2004; Anguelova and Webster, 2006). Part of these variations is due to differences in methods of extracting $W$ from still and video images. Indeed, the spread of $W$ data has decreased in recently published in situ data sets as image processing improved and data volume increased (de Leeuw et al., 2011). However, an order-of-magnitude scatter (spread) of $W$ data remains, suggesting that $U_{10}$ alone cannot fully predict the $W$ variability. Other factors, such as atmospheric stability (often expressed in terms of airsea temperature difference) and/or sea surface temperature (SST) (Monahan and O'Muircheartaigh, 1986), friction velocity (combining wind speed and thermal stability, e.g., Wu, 1988; Stramska and Petelski, 2003), wave field (SAL13), and surfactant activity (Callaghan et al., 2013), have been indicated to affect $W$ with implications for the SSA production. Thus, parameterizations of $W$ that use different, or include additional (secondary), forcing parameters to better model the spread of $W$ data due to natural whitecap variability have been sought (Monahan and O'Muircheartaigh, 1986; Zhao and Toba, 2001; Goddijn-Murphy et al., 2011; Norris et al., 2013b; Ovadnevaite et al., 2014; Savelyev et al., 2014).

An alternative approach to address the variability of $W$ is to use whitecap fraction estimates from satellite-based observations of the sea state, because such observations provide long-term global data sets which encompass a wide range of meteorological and environmental conditions, as opposed to local measurement campaigns during which a limited variation of conditions is usually encountered. Brightness temperature $T_{\mathrm{B}}$ of the ocean surface measured from satellitebased radiometers at microwave frequencies has been successfully used to retrieve geophysical variables, including wind speed (Wentz, 1997; Bettenhausen et al., 2006; Meissner and Wentz, 2012). The feasibility of estimating $W$ from $T_{\mathrm{B}}$ has also been demonstrated (Wentz, 1983; Pandey and Kakar, 1982; Anguelova and Webster, 2006).

Anguelova et al. $(2006,2009)$ used WindSat data (Gaiser et al., 2004) to further develop the method of estimating $W$ from $T_{\mathrm{B}}$, and compiled a database of satellite-based $W$ data accompanied by additional variables (hereafter referred to as the whitecap database). An early version of the whitecap database combines whitecap fraction at two frequencies $\left(W_{10}\right.$ for $10 \mathrm{GHz}$ and $W_{37}$ for $37 \mathrm{GHz}$ ), with wind speed $U_{10}$, wind direction $U_{\mathrm{dir}}$, and SST $T$. Figure 1a shows an example of the global $W$ distribution from WindSat for a randomly chosen day from this whitecap database. An extended version of the whitecap database was compiled later to include three additional environmental variables: air temperature, significant wave height, and peak wave period (Anguelova et al., 2010).
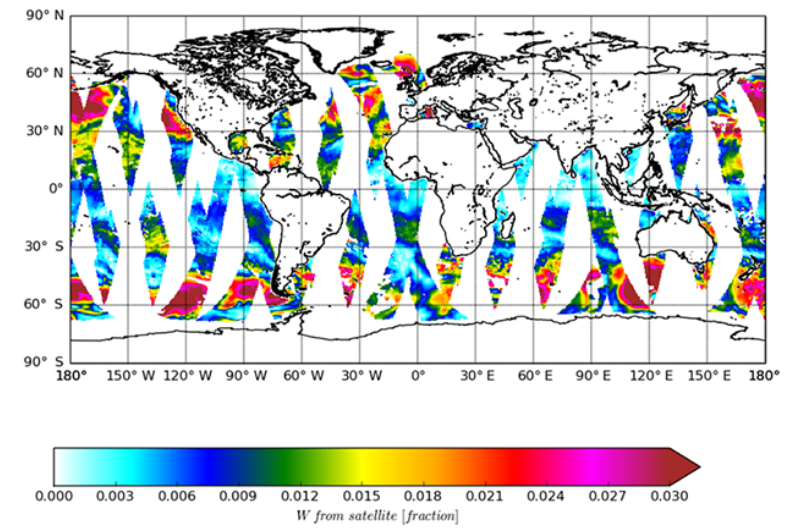

(a)

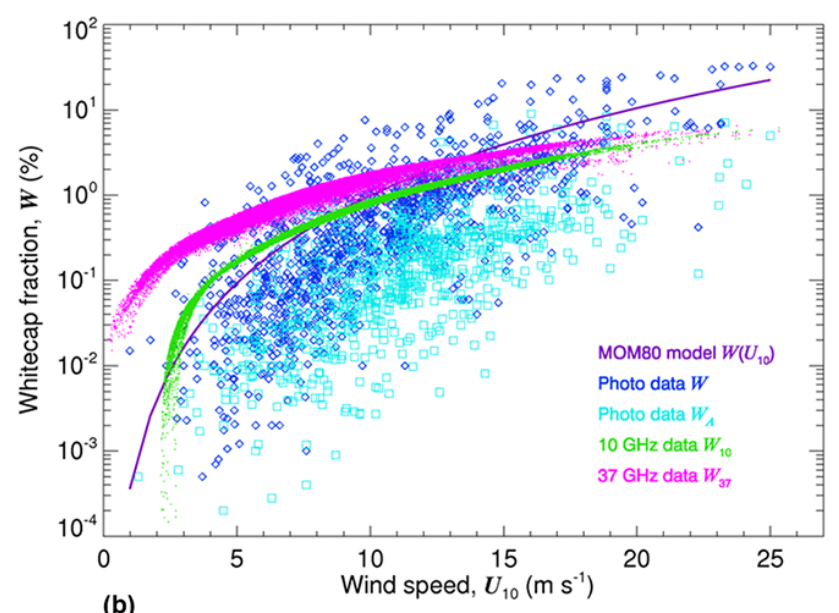

(b)

Figure 1. Satellite estimates of $W$ data at $37 \mathrm{GHz}$ for 11 March 2006. (a) Map $\left(0.5^{\circ} \times 0.5^{\circ}\right)$ of ascending and descending passes for $W$ at $37 \mathrm{GHz}$; (b) $W$ at 10 and $37 \mathrm{GHz}$ (green and magenta symbols, respectively) compared to historical photographic data including total $W$ (diamonds) and active whitecap fraction $W_{\mathrm{A}}$ (squares). Parameterization $W\left(U_{10}\right)$ of Monahan and O'Muircheartaigh (1980, MOM80) (purple line) is shown for reference.

Salisbury et al. (2013) analyzed the extended whitecap database and showed that satellite-based $W$ values carry a wealth of information on the variability of $W$. In particular, these authors showed that the global distribution of satellitebased $W$ values differs from that obtained using a conventional $W\left(U_{10}\right)$ parameterization with important implications for modeling SSA production rate in global climate models (GCMs) and chemical transport models (CTMs) (Salisbury et al., 2014). Salisbury et al. (2013) proposed a new $W\left(U_{10}\right)$ parameterization in power law form using satellite-based $W$ data over the entire globe for a full year. They derived wind speed exponents which are approximately quadratic for different data sets: 


$$
\begin{aligned}
& W_{10}=4.6 \times 10^{-3} \times U_{10}^{2.26} ; \quad 2<U_{10} \leq 20 \mathrm{~m} \mathrm{~s}^{-1}, \\
& W_{37}=3.97 \times 10^{-2} \times U_{10}^{1.59} ; \quad 2<U_{10} \leq 20 \mathrm{~m} \mathrm{~s}^{-1},
\end{aligned}
$$

where $W$ is expressed in percent. These exponents are significantly different from the cubic and higher wind speed dependences proposed by Callaghan et al. (2008, hereafter CAL08):

$$
\begin{gathered}
W=3.18 \times 10^{-3}\left(U_{10}-3.70\right)^{3} ; \\
3.70<U_{10} \leq 11.25 \mathrm{~m} \mathrm{~s}^{-1} \\
W=4.82 \times 10^{-4}\left(U_{10}+1.98\right)^{3} ; \\
9.25<U_{10} \leq 23.09 \mathrm{~m} \mathrm{~s}^{-1},
\end{gathered}
$$

and Monahan and O'Muircheartaigh (1980, hereafter MOM80):

$$
W\left(U_{10}\right)=3.84 \times 10^{-6} U_{10}^{3.41} .
$$

The MOM80 parameterization was derived on the basis of the data sets of Monahan (1971) and Toba and Chaen (1973). Most of the wind speed values from these two data sets are up to $12 \mathrm{~m} \mathrm{~s}^{-1}$ with only $10 \%$ of the data points for winds up to $17 \mathrm{~m} \mathrm{~s}^{-1}$. The range of SST is from 17 to $31^{\circ} \mathrm{C}$. Monahan and O'Muircheartaigh (1986) emphasized that this is a regionally specific function, but its widespread adoption in global models led to its application at wind speeds and SSTs well beyond its range of validity.

In this study, we explore the utility of the satellite-based $W$ data from a standpoint of predicting SSA production rate. Whitecaps are used as a proxy for the amount of bubbles at the ocean surface. When these bubbles burst, they generate sea spray droplets which in turn transform to SSAs when they equilibrate with the surroundings (Blanchard, 1983). Bursting bubbles produce film and jet droplets, whereas at high wind speeds, exceeding about $9 \mathrm{~m} \mathrm{~s}^{-1}$, additional sea spray is directly produced as droplets which are blown off the wave crests (Monahan et al., 1983). These spume droplets are larger than the bubble-mediated SSA droplets (Andreas, 1992). In this study, we will focus on bubble-mediated production of sea spray.

Sea spray aerosols are important for the climate system because, due to the vast extent of the ocean, SSA particles are amongst the largest aerosol sources globally (de Leeuw et al., 2011). SSA particles contribute to the scattering of shortwave electromagnetic radiation and thus to their direct radiative effect on climate. Also, having high hygroscopicity, SSA particles are a source for the formation of cloud condensation nuclei (Ghan et al., 1998; O'Dowd et al., 1999) and as such influence cloud microphysical properties and thus exert indirect radiative effects on the climate system. While residing in the atmosphere, SSAs provide surface and volume for a range of multiphase and heterogeneous chemical processes (Andreae and Crutzen, 1997). Through such chemi- cal processes, the SSAs contribute to the production of inorganic reactive halogens (Cicerone, 1981; Graedel and Keene, 1996; Keene et al., 1999; Saiz-Lopez and von Glasow, 2012), participate in the production or destruction of surface ozone (Keene et al., 1990; Barrie et al., 1988; Koop et al., 2000), and provide a sink in the sulfur atmospheric cycle (Chameides and Stelson, 1992; Luria and Sievering, 1991; Sievering et al., 1992, 1995).

The modeling of all these processes in GCMs and CTMs starts with calculation of the production rate of SSA particles (termed also SSA production flux, SSA generation, or SSA emission). A sea spray source function (SSSF) is used to calculate SSA production flux - the number of SSA particles produced per unit of sea surface area per unit of time. The most commonly used SSSF, proposed by Monahan et al. (1986, hereafter M86), estimates SSA emission by the indirect, bubble-mediated mechanism. Based on the discrete whitecap method, the SSSF of M86 is formulated in terms of $W\left(U_{10}\right)$, as defined by MOM80 (Eq. 3), whitecap decay timescale $\tau$, and the aerosol productivity per unit whitecap $\mathrm{d} E / \mathrm{d} r:$

$$
\begin{aligned}
\frac{\mathrm{d} F}{\mathrm{~d} r_{80}} & =\frac{W\left(U_{10}\right)}{\tau} \frac{\mathrm{d} E}{\mathrm{~d} r_{80}} \\
& =1.373 \cdot U_{10}^{3.41} \cdot r_{80}^{-3}\left(1+0.057 r_{80}^{1.05}\right) \times 10^{1.19 e^{-B^{2}}} .
\end{aligned}
$$

In Eq. (4), MOM80 had used a constant value for the timescale $\tau=3.53 \mathrm{~s}, r_{80}$ is the droplet radius at a relative humidity of $80 \%$, and the exponent $B$ is defined as $B=(0.38-$ $\left.\lg r_{80}\right) / 0.65$. The term $\mathrm{d} E / \mathrm{d} r$, associated with the sea spray size distribution, determines the shape of the SSSF (i.e., shape factor); the term $W / \tau$ is a scaling (or magnitude) factor, as it links predetermined SSA production per unit whitecap area with the amount of whitecapping in different regions at different seasons. Refer to Lewis and Schwartz (2004), de Leeuw et al. (2011), and Callaghan (2013) for clear distinction of the discrete whitecap method from the continuous whitecap method.

Estimates of SSA production fluxes using the discrete whitecap method still vary widely (Lewis and Schwartz, 2004; de Leeuw et al., 2011), precluding reliable estimates of the direct and indirect effects by SSAs in GCMs, as well as the outcome of heterogeneous chemical reactions taking place in and on SSA particles in CTMs. The wide spread of predicted SSA emissions is caused by a combination of uncertainties coming from both the magnitude and the shape factors of the used SSSFs. The uncertainties associated with the magnitude factor include difficulties of measuring $W$ and $\tau$ and their natural variability, which affects the $W\left(U_{10}\right)$ parameterizations. The assumptions of the discrete whitecap method (detailed in Sect. 2.4) also contribute to the uncertainty. Added to these are the uncertainties associated with the shape factor, such as its natural variability and the model chosen to parameterize the SSA size distribution. A source of uncertainty is the difficulty of directly measuring SSA fluxes 
which are used to develop and/or constrain SSSFs. When measurements of SSA concentrations are used to develop an SSSF, uncertainty comes from the deposition velocity model used to convert the concentrations to fluxes (e.g., Smith et al., 1993; Savelyev et al., 2014).

Aside from addressing uncertainties due to sea spray measuring techniques, there are two possible ways to improve the performance of a whitecap-based SSSF as regards the physical processes involved. One way is to address variations and uncertainties in the size-resolved productivity $\mathrm{d} E / \mathrm{d} r_{80}$ (i.e., the shape factor in the SSSF), for instance, by including the organic matter contribution to SSA at submicron sizes (O'Dowd et al., 2004; Albert et al., 2012) and/or by accounting for its variations with environmental factors instead of keeping it constant for all conditions (de Leeuw et al., 2011; Norris et al., 2013a; Savelyev et al., 2014). Another way is to address the variations and uncertainties in the whitecap fraction $W$ and timescale $\tau$ (i.e., the magnitude factor in the SSSF) by steady improvements of the $W$ and $\tau$ measurements and by accounting for their natural variability. Both approaches are expected to reduce, or at least to better account for, the variations and uncertainties in parameterizing SSA flux.

Here, we report on a study investigating the second of these two routes, namely - how using $W$ data, which carry information for secondary factors, would influence the SSA production flux. The objective is to assess how much of the uncertainty in the SSA flux can be explained with the natural variability of $W$. Using the early version of the whitecap database (consisting of data for $W_{10}, W_{37}, U_{10}, U_{\mathrm{dir}}$, and $T$ ), we parameterize the $W$ variability in terms of $U_{10}$ and $T$. Our approach (Sect. 2) involves three steps. We first assess the satellite-based whitecap database to evaluate the wind speed dependence of $W$ over as wide a range of $U_{10}$ values as possible (Sect. 3.1.1). In assessing the $W$ database, we also evaluate (i) the impact of an intrinsic correlation between $W$ and $U_{10}$, which could have been introduced in the process of estimating $W$ from $T_{\mathrm{B}}$ (Sect. 3.1.2); (ii) the influence of the wave field on $W$ variability using rising and waning wind speeds as a proxy for wave development (Sect. 3.1.3). The $W\left(U_{10}\right)$ expression resulting from this analysis adjusts the trend of $W$ with $U_{10}$ to the concerted, globally averaged influence of all secondary factors implicitly. We next apply the established $W\left(U_{10}\right)$ expression to $W$ data on regional scales in order to assess the variability caused by secondary factors in different locations during different seasons (Sect. 3.2). We analyze the regional variations of $W$ remaining after the implicit adjustment with the $W\left(U_{10}\right)$ expression and parameterize them explicitly in terms of SST. The new $W\left(U_{10}, T\right)$ parameterization is compared to $W\left(U_{10}\right)$ of MOM80 and SAL13 (Sect. 3.3) in order to assess to what extent SST can account for the $W$ variability. Finally, the new $W\left(U_{10}, T\right)$ parameterization is used to estimate SSA emissions and compare results to previous predictions of SSA emissions (Sect. 3.4).

\section{Methods}

To achieve the study objective formulated above, the main task is to develop a parameterization of $W$ that accounts for both the trend and the spread of the $W$ data. Expressions $W\left(U_{10}\right)$ model (predict) the trend of the whitecap fraction with wind speed. The inclusion of additional variables in $W\left(U_{10}\right)$ relationships should be able to model (predict) the spread of the $W$ data caused by natural variability. The approach described below aims at deriving an expression $W\left(U_{10}, T\right)$ that fulfils these two requirements.

\subsection{Approach to derive a whitecap fraction parameterization}

Reasoning about a series of questions shaped our approach to parameterizing $W$ and justified the choices we made for its implementation (Sect. 2.3). We first considered why we need to parameterize $W$ instead of using satellite-based $W$ data directly. A major benefit of using satellite-based $W$ data directly in an SSSF is that these data reflect the amount and persistence of whitecaps as they are formed by both primary and secondary forcing factors acting at a given location. This approach limits the uncertainty to that of estimating $W$ from satellite measurements and does not add uncertainty from deriving an expression for $W\left(U_{10}\right)$ or $W\left(U_{10}, T\right.$, etc.). However, such an approach would limit global predictions of SSA emissions to monthly values because a satellite-based $W$ data set does not provide daily global coverage; i.e., one would need data like those in Fig. 1a for at least 2 weeks (and more for good estimates of the uncertainties) in order to have full coverage of the globe.

Alternatively, a parameterization of whitecap fraction derived from satellite-based $W$ data can provide daily estimates of SSA emissions using readily available daily data of wind speed and other variables. Importantly, such a parameterization will be globally applicable because the whitecap fraction data cover the full range of meteorological conditions encountered over most of the world oceans. Because the availability of a large number of $W$ data would ensure low error in the derivations of the $W\left(U_{10}\right)$ or $W\left(U_{10}, T\right.$, etc.) expressions, we proceed with deriving a parameterization for $W$ using the data in the whitecap database (Sect. 2.2.1).

The next question to consider was how to account for the influence of secondary factors. Generally, to fully account for the variability of whitecap fraction, a parameterization of $W$ would involve wind speed and many additional forcings explicitly to derive an expression $W\left(U_{10}, T\right.$, etc.) (MOM80; Monahan and O'Muircheartaigh, 1986; Anguelova and Webster, 2006). Using the early version of the whitecap database in this study, we start with parameterization $W\left(U_{10}, T\right)$.

The question that arises next is how to combine the different dependences of $W$. One possibility is to use a singlevariable regression to extract the $W$ dependence on each variable separately, e.g., $W\left(U_{10}\right)$ and $W(T)$. Then, these can be 
combined to derive an expression for their effects in concert, e.g., $W\left(U_{10}, T\right)=W\left(U_{10}\right) W(T)$. While variables like $T$, atmospheric stability, surfactants, etc. influence $W$, they do not cause whitecapping. So a parameterization formulated with dedicated $W(T)$ and other expressions may put undue weight on such influences. This approach can be pursued when we have enough information to judge the relative importance of each influence (e.g., Anguelova et al., 2010, their Fig. 6) and include it in a combined expression with a respective weighting factor.

Previous experience points to another possibility to combine causal variables like $U_{10}$ and influential variables like $T$ and the likes. The Monahan and O'Muircheartaigh (1986) analysis of five data sets showed that the variability of $W$ caused by SST (and the atmospheric stability) significantly affect the coefficients in the wind speed dependence $W\left(U_{10}\right)$, especially the wind speed exponent. The survey of $W\left(U_{10}\right)$ parameterizations by Anguelova and Webster (2006, their Tables 1 and 2) also clearly shows that each campaign conducted in different regions and conditions comes up with a specific wind speed exponent. This strongly suggests that the influence of secondary factors is implicitly expressed as a change of the wind speed exponent. On the basis of their principal component analysis, SAL13 also suggested that in describing the $W$ variability, it is more effective to combine individual variables with wind speed. On this ground, we proceed to obtain $W\left(U_{10}, T\right)$ as a wind speed dependence $W\left(U_{10}\right)$ whose regression (or parametric) coefficients vary with SST.

How can this goal be realized, knowing that the satellitebased $W$ data carry information for the effect of $U_{10}$ and all other factors? One possible way to proceed is to (i) express the mean trend in the $W$ data associated with the globally averaged conditions of $U_{10}$ and all other factors, then (ii) quantify the fluctuations of regional $W$ data around this mean trend as a function of a specific secondary factor. Here, step (i) implicitly accounts for the effects of all secondary factors on $W$, while step (ii) explicitly quantifies the effect of a given factor on $W$. That is, the explicit formulation of the parametric coefficients accounts only partially for the full effect of a given secondary factor; it adds to the implicit account via the mean trend of $W$ with $U_{10}$. To realize this concept, we first analyze the global $W$ data set to identify a general wind speed dependence $W\left(U_{10}\right)$ for the mean trend. Then, our analysis of regional $W$ data helps to asses to what extent can SST account for the variations of the regression coefficients in a $W\left(U_{10}\right)$ dependence.

The important question now is what functional form we should use for the general (mean) $W\left(U_{10}\right)$ dependence. Equations (1)-(3) exemplify the functional forms usually employed to express $W\left(U_{10}\right)$ :
$W=a U_{10}^{n}$
$W=a\left(U_{10}+b\right)^{3}$.

A general $W\left(U_{10}\right)$ dependence derived using Eq. (5a) would provide an empirical wind speed exponent $n$ determined from available data sets, as MOM80 did using the available data sets at the time (Sect. 1). The wider the range of conditions represented by the data sets is the closer the resulting $W\left(U_{10}\right)$ dependence would be to average conditions globally and seasonally.

A general $W\left(U_{10}\right)$ dependence derived using Eq. (5b) would provide a physically based wind speed exponent $(n=$ 3) consistent with dimensional (scaling) arguments. Namely, because $W$ is related to the rate at which the wind supplies energy to the sea, $W$ should be proportional to the cube of the friction velocity $u_{*}$ (Monahan and O'Muircheartaigh, 1986; Wu, 1988). On this basis, Monahan and Lu (1990) related $W^{1 / 3}$ to $U_{10}$ and derived the cubic power law in Eq. (5b). Subsequently, this relationship was used successfully in whitecap data analyses (e.g., Asher and Wanninkhof, 1998; CAL08). Coefficient $b$ in Eq. (5b) is included because it is preferable for a $W\left(U_{10}\right)$ relationship to involve a finite $y$ intercept (Monahan and O'Muircheartaigh, 1986). A negative $y$ intercept determines $b$ from the $x$ intercept and is usually interpreted as the threshold wind speed for whitecap inception.

A modified version of Eq. (5) combines the merits of both formulations into the form

$W=a\left(U_{10}+b\right)^{n}$,

where the wind speed exponent is adjustable (i.e., a free parameter) and a finite $y$ intercept is included. A general $W\left(U_{10}\right)$ dependence derived using Eq. (6) would provide a wind speed exponent as dictated by the whitecap database. Any of the three formulations (Eqs. 5 and 6) can produce a viable general $W\left(U_{10}\right)$ dependence, the empirical ones representative of the average conditions of the world oceans and the physical one supported by sound reasoning.

\subsection{Data sets}

To implement the approach thus formulated, we use the whitecap database on a global scale for the general $W\left(U_{10}\right)$ dependence, and regional $W$ subsets extracted from the whitecap database for the SST analysis. In describing the data sets used, we start with the whitecap database (Sect. 2.2.1). The considerations given to extract regional data sets from it are described in Sect. 2.2.2. We also introduce the data from the European Centre for Medium range Weather Forecasting (ECMWF) used in this study as an independent source to investigate possible intrinsic correlation among the entries of the whitecap database (Sect. 2.2.3). 


\subsubsection{Whitecap database}

Anguelova and Webster (2006) describe in detail the general concept of estimating the whitecap fraction $W$ from measurements of the brightness temperature $T_{\mathrm{B}}$ of the ocean surface with satellite-borne microwave radiometers. Salisbury et al. (2013) describe the basic points of the algorithm estimating $W$ (hereafter referred to as the $W\left(T_{\mathrm{B}}\right)$ algorithm). Briefly, the algorithm obtains $W$ by using measured $T_{\mathrm{B}}$ data for the composite emissivity of the ocean surface and modeled $T_{\mathrm{B}}$ data for the emissivity of the rough sea surface and areas that are covered with foam (Bettenhausen et al., 2006; Anguelova and Gaiser, 2013). An atmospheric model is necessary to evaluate the contribution from the atmosphere to $T_{\mathrm{B}}$. Minimization of the differences between the measured and modeled $T_{\mathrm{B}}$ data in the $W\left(T_{\mathrm{B}}\right)$ algorithm ensures minimal dependence of the $W$ estimates on model assumptions and input variables.

Wind speed $U_{10}$ is one of the required inputs to the atmospheric, roughness, and foam models (Anguelova and Webster, 2006; Salisbury et al., 2013). Wind speed data come from the SeaWinds scatterometer on the QuikSCAT platform or from the Global Data Assimilation System (GDAS), based on whichever matches up better with the WindSat data in time and space within $60 \mathrm{~min}$ and $25 \mathrm{~km}$; hereafter, we refer to both QuikSCAT or GDAS wind speed values as $U_{10}$ from QuikSCAT or $U_{10 \mathrm{QSCAT}}$. The use of $U_{10 \mathrm{QSCAT}}$ in the estimates of satellite-based $W$ is anticipated to lead to some intrinsic correlation when/if a relationship between $W$ and $U_{10 \mathrm{QSCAT}}$ is sought.

The $W$ data used in this study are obtained from $T_{\mathrm{B}}$ at 10 and $37 \mathrm{GHz}, W_{10}$ and $W_{37}$; data for $37 \mathrm{GHz}$ are shown in Fig. 1a. The $W_{10}$ and $W_{37}$ data approximately represent different stages of the whitecaps because of different sensitivity of microwave frequencies to foam thickness (Anguelova and Gaiser, 2011). Data of $W_{10}$ are an upper limit for predominantly active wave breaking (stage A whitecaps; Monahan and Woolf, 1989) partially mixed with decaying (stage B) whitecaps, while $W_{37}$ data quantify both active and decaying whitecaps. Because decaying foam covers a much larger area of the ocean surface than active whitecaps (Monahan and Woolf, 1989), $W_{37}$ data are usually larger than $W_{10}$ data. Comparisons to historic and contemporary in situ $W$ data in Fig. $1 \mathrm{~b}$ confirm the approximate representations of stage A whitecaps (cyan squares) and A plus B whitecaps (blue diamonds) by $W_{10}$ (green) and $W_{37}$ (magenta), respectively. Anguelova et al. (2009) have quantified the differences between satellite-based and in situ $W$ data using both previously published measurements and time-space matchups of $W$, and discussed possible reasons for the discrepancies.

The satellite-based $W$ data are gridded into a $0.5^{\circ} \times 0.5^{\circ}$ grid cell together with the variables accompanying each $W$ data point, namely $U_{10 \mathrm{QSCAT}}, T$ from GDAS, time (average of the times of all samples falling in each grid cell), and statistical data generated during the gridding including the root

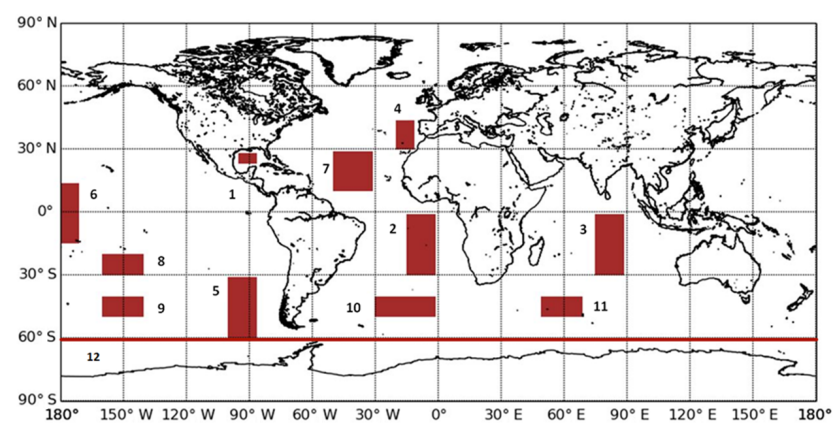

Figure 2. Selected regions to determine regional variations of $W\left(U_{10}\right)$.

mean square (rms) error, standard deviation (SD), and count (the number of individual samples in a satellite swath averaged to obtain the daily mean $W$ for a grid cell). In this study, we used daily matchups of $W, U_{10}$, and $T$ data for each grid cell for the year 2006. To reiterate, this data set - consisting of $W_{10}$ and $W_{37}$ accompanied with three environmental variables $\left(U_{10}, U_{\mathrm{dir}}\right.$ and $\left.T\right)$ - is an early version of the whitecap database; the extended $W$ database used by SAL13 (Sect. 1) contains three additional variables suitable to quantify explicitly the effects of wave field and atmospheric stability on $W$. Due to large data gaps in both space and time, the daily $W$ data cannot be interpolated to provide better coverage (Fig. 1a). Therefore, only the available data are used without filling the gaps for areas where data are lacking. This global data set was used to assess the globally averaged wind speed dependence of $W$.

\subsubsection{Regional data sets}

The annual global $W$ distributions show regions with valid data points ranging from 100 to 300 samples per grid cell per year when both ascending and descending satellite passes are considered. Thus, different regions were selected using two criteria, namely (i) regions with a high number of valid data points, and (ii) a selection representative of different conditions in the Northern and Southern hemispheres ( $\mathrm{NH}$ and $\mathrm{SH})$.

With these criteria, 12 regions of interest were selected (Fig. 2) and $W, U_{10}$, and $T$ data for each region were extracted from the whitecap database. The coordinates of the selected regions are listed in Table 1, together with the corresponding number of samples (data points) and minimum, maximum, mean, and median values for wind speed and SST for January and July. For $90 \%$ of the regional and monthly data used in the study, the percent difference (PD, defined as the difference between two values divided by the average of the two values) between mean and median values of $U_{10}$ and $T$ is less than 4 and $9.5 \%$, respectively. With medians and means approximately the same, the $U_{10}$ and $T$ data have normal distributions; i.e., outliers, though existing, do not affect 
Table 1. Coordinates (longitude and latitude), number of data points are given together with range, mean and median values for wind speed and SST of all selected regions for (a) January 2006 and (b) July 2006. CIs at $95 \%$ level are given for regions 4, 5, 6, and 12, whose seasonal variations are plotted in Fig. 3.

\begin{tabular}{|c|c|c|c|c|c|c|c|c|c|c|c|}
\hline \multicolumn{12}{|c|}{ (a) January 2006} \\
\hline \multirow[t]{2}{*}{ Region } & \multirow[t]{2}{*}{ Long. } & \multirow[t]{2}{*}{ Lat. } & \multirow[t]{2}{*}{ Samples } & \multicolumn{4}{|c|}{ Wind speed $\left(\mathrm{m} \mathrm{s}^{-1}\right)$} & \multicolumn{4}{|c|}{$\operatorname{SST}\left({ }^{\circ} \mathrm{C}\right)$} \\
\hline & & & & Range & Mean & $95 \% \mathrm{CI}$ & Median & Range & Mean & $95 \% \mathrm{CI}$ & Median \\
\hline 1 & $86-95^{\circ} \mathrm{W}$ & $23-28^{\circ} \mathrm{N}$ & 18896 & $1.3-15.7$ & 7.5 & & 7.6 & $19.4-26.0$ & 23.8 & & 24.1 \\
\hline 2 & $1-15^{\circ} \mathrm{W}$ & $1-30^{\circ} \mathrm{S}$ & 169128 & $0.2-12.9$ & 6.4 & & 6.4 & $21.4-27.8$ & 24.2 & & 24.1 \\
\hline 3 & $75-89^{\circ} \mathrm{E}$ & $1-30^{\circ} \mathrm{S}$ & 169056 & $0.0-13.4$ & 7.0 & & 7.2 & $23.0-29.4$ & 26.8 & & 27.3 \\
\hline 4 & $11-20^{\circ} \mathrm{W}$ & $30-44^{\circ} \mathrm{N}$ & 49760 & $0.2-19.6$ & 8.0 & $2.7 \times 10^{-2}$ & 7.6 & $13.3-20.4$ & 16.4 & $1.5 \times 10^{-2}$ & 16.3 \\
\hline 5 & $86-100^{\circ} \mathrm{W}$ & $31-60^{\circ} \mathrm{S}$ & 200360 & $0.5-23.0$ & 8.7 & $1.3 \times 10^{-2}$ & 8.7 & $4.8-24.1$ & 12.7 & $2.2 \times 10^{-2}$ & 11.7 \\
\hline 6 & $171-180^{\circ} \mathrm{W}$ & $15^{\circ} \mathrm{S}-14^{\circ} \mathrm{N}$ & 123328 & $0.6-15.6$ & 8.2 & $1.2 \times 10^{-2}$ & 8.2 & $26.2-30.4$ & 28.4 & $0.6 \times 10^{-2}$ & 28.2 \\
\hline 7 & $31-50^{\circ} \mathrm{W}$ & $10-29^{\circ} \mathrm{N}$ & 90640 & $0.3-20.0$ & 8.8 & & 9.0 & $20.1-27.9$ & 24.9 & & 25.3 \\
\hline 8 & $140-160^{\circ} \mathrm{W}$ & $20-30^{\circ} \mathrm{S}$ & 50040 & $0.5-16.3$ & 6.8 & & 6.7 & $22.2-29.1$ & 26.3 & & 26.6 \\
\hline 9 & $140-160^{\circ} \mathrm{W}$ & $40-50^{\circ} \mathrm{S}$ & 41840 & $0.1-20.6$ & 6.9 & & 6.5 & $9.3-18.2$ & 13.2 & & 13.1 \\
\hline 10 & $0-30^{\circ} \mathrm{W}$ & $40-50^{\circ} \mathrm{S}$ & 133080 & $0.5-26.4$ & 9.4 & & 9.3 & $3.2-16.7$ & 9.6 & & 9.3 \\
\hline 11 & $50-70^{\circ} \mathrm{E}$ & $40-50^{\circ} \mathrm{S}$ & 50784 & $0.5-21.6$ & 9.6 & & 9.6 & $3.2-17.4$ & 9.6 & & 9.5 \\
\hline 12 & $180^{\circ} \mathrm{E}-180^{\circ} \mathrm{W}$ & $60-90^{\circ} \mathrm{S}$ & 576576 & $0.2-20.9$ & 7.0 & $0.8 \times 10^{-2}$ & 6.7 & $-1.9-8.0$ & 1.8 & $0.5 \times 10^{-2}$ & 1.4 \\
\hline \multicolumn{12}{|c|}{ (b) July 2006} \\
\hline \multirow[t]{2}{*}{ Region } & \multirow[t]{2}{*}{ Long. } & \multirow[t]{2}{*}{ Lat. } & \multirow[t]{2}{*}{ Samples } & \multicolumn{4}{|c|}{ Wind speed $\left(\mathrm{m} \mathrm{s}^{-1}\right)$} & \multicolumn{4}{|c|}{$\operatorname{SST}\left({ }^{\circ} \mathrm{C}\right)$} \\
\hline & & & & Range & Mean & $95 \% \mathrm{CI}$ & Median & Range & Mean & $95 \%$ CI & Median \\
\hline 1 & $86-95^{\circ} \mathrm{W}$ & $23-28^{\circ} \mathrm{N}$ & 13848 & $0.4-10.0$ & 4.5 & & 4.4 & $28.7-30.5$ & 29.5 & & 29.4 \\
\hline 2 & $1-15^{\circ} \mathrm{W}$ & $1-30^{\circ} \mathrm{S}$ & 189600 & $0.2-14.0$ & 6.6 & & 6.6 & $17.7-27.1$ & 23.2 & & 23.7 \\
\hline 3 & $75-89^{\circ} \mathrm{E}$ & $1-30^{\circ} \mathrm{S}$ & 195424 & $0.6-15.4$ & 8.0 & & 8.1 & $18.8-30.0$ & 25.4 & & 25.9 \\
\hline 4 & $11-20^{\circ} \mathrm{W}$ & $30-44^{\circ} \mathrm{N}$ & 43040 & $0.7-14.0$ & 6.7 & $2.2 \times 10^{-2}$ & 6.6 & $16.9-23.3$ & 20.4 & $1.3 \times 10^{-2}$ & 20.5 \\
\hline 5 & $86-100^{\circ} \mathrm{W}$ & $31-60^{\circ} \mathrm{S}$ & 257496 & $0.7-22.7$ & 9.8 & $1.4 \times 10^{-2}$ & 9.6 & $2.5-19.1$ & 9.3 & $1.6 \times 10^{-2}$ & 8.3 \\
\hline 6 & $171-180^{\circ} \mathrm{W}$ & $15^{\circ} \mathrm{S}-14^{\circ} \mathrm{N}$ & 133096 & $0.1-14.8$ & 6.0 & $1.1 \times 10^{-2}$ & 6.0 & $26.9-29.7$ & 28.8 & $0.3 \times 10^{-2}$ & 29.0 \\
\hline 7 & $31-50^{\circ} \mathrm{W}$ & $10-29^{\circ} \mathrm{N}$ & 88304 & $0.4-13.6$ & 7.4 & & 7.4 & $23.6-28.0$ & 26.0 & & 26.1 \\
\hline 8 & $140-160^{\circ} \mathrm{W}$ & $20-30^{\circ} \mathrm{S}$ & 47504 & $0.7-24.7$ & 6.9 & & 6.2 & $18.8-27.0$ & 23.2 & & 23.4 \\
\hline 9 & $140-160^{\circ} \mathrm{W}$ & $40-50^{\circ} \mathrm{S}$ & 52736 & $0.5-21.0$ & 10.1 & & 10.3 & $8.2-14.1$ & 10.9 & & 10.8 \\
\hline 10 & $0-30^{\circ} \mathrm{W}$ & $40-50^{\circ} \mathrm{S}$ & 160192 & $0.9-28.9$ & 10.8 & & 10.8 & $1.8-14.6$ & 8.3 & & 8.3 \\
\hline 11 & $50-70^{\circ} \mathrm{E}$ & $40-50^{\circ} \mathrm{S}$ & 49344 & $1.1-28.2$ & 12.9 & & 12.7 & $2.1-16.1$ & 8.3 & & 7.8 \\
\hline 12 & $180^{\circ} \mathrm{E}-180^{\circ} \mathrm{W}$ & $60-90^{\circ} \mathrm{S}$ & 177240 & $0.8-29.1$ & 11.7 & $1.9 \times 10^{-2}$ & 11.9 & $-1.3-4.3$ & 1.7 & $0.4 \times 10^{-2}$ & 1.7 \\
\hline
\end{tabular}

the mean values significantly. All analyses presented here use the mean $U_{10}$ and $T$ values.

Figure 3 shows the seasonal cycles of the mean $U_{10}$ and $T$ values for 4 of the selected 12 regions $(4,5,6$, and 12) chosen to visualize the full range of regional variations of $U_{10}$ and $T$ data. With the large number of samples, the mean $U_{10}$ and $T$ values plotted in Fig. 3 are determined within $95 \%$ confidence interval (CI) of the order of $10^{-2}$ (Table 1). That is, any uncertainty due to sampling is removed, and Fig. 3 represents seasonal variations well, which we will use in our analyses. Variability of SST within each region is visualized with error bars ( $\pm 1 \mathrm{SD})$ in Fig. 3b. The distinct regional SST variations suggest the effect of SST can be discerned with our data and thus used to parameterize the effect of SST on $W$. The variability of $U_{10}$ within regions is higher (wider error bars are not plotted to avoid clutter), which suggests that the use of the global data set to obtain a generalized wind speed dependence of $W$ (Sect. 2.1) is reasonable.

Regions 2-11 are all in the open ocean; region 1 was selected for its landlocked position (Fig. 2). Region 6 in the Pacific doldrums is used as a reference for the lower limit of $U_{10}$ (Fig. 3a), while region 12 is included to represent the lowest $T$ values (Fig. 3b). Four regions (2, 3, 7, and 8) are at latitudes between 0 and $30^{\circ} \mathrm{S}$ and $\mathrm{N}$ (tropics and subtropics) representing the trade winds zone. These are regions with persistent (easterly) winds blowing over approximately the same fetches (except region 8) in oceans with different salinity (Tang et al., 2014) and primary production (Falkowski et al., 1998) (a proxy for surfactant concentrations). Region 4 is in the $\mathrm{NH}$ temperate zone representing long-fetched westerly winds. Region 5 covers the latitudes between 40 and $50^{\circ} \mathrm{S}$ known as "The Roaring Forties" for the strong westerly winds there, and is characterized with longer fetch. Differences in the seasonal cycles of $U_{10}$ and $T$ in regions 4 and 5 (Fig. 3) suggest more uniform conditions and longer fetches in the SH temperate zone. We have chosen regions 8 and 9 to represent different zonal conditions and to gauge the effect of narrower range of SST variations (as compared to the SST range in region 5). Chosen at the same latitude, regions 9-11 have approximately the same SST, salinity, and surfactants but represent different wind fetches, shortest for region 10 and longest for region 9 . Overall, the chosen re- 

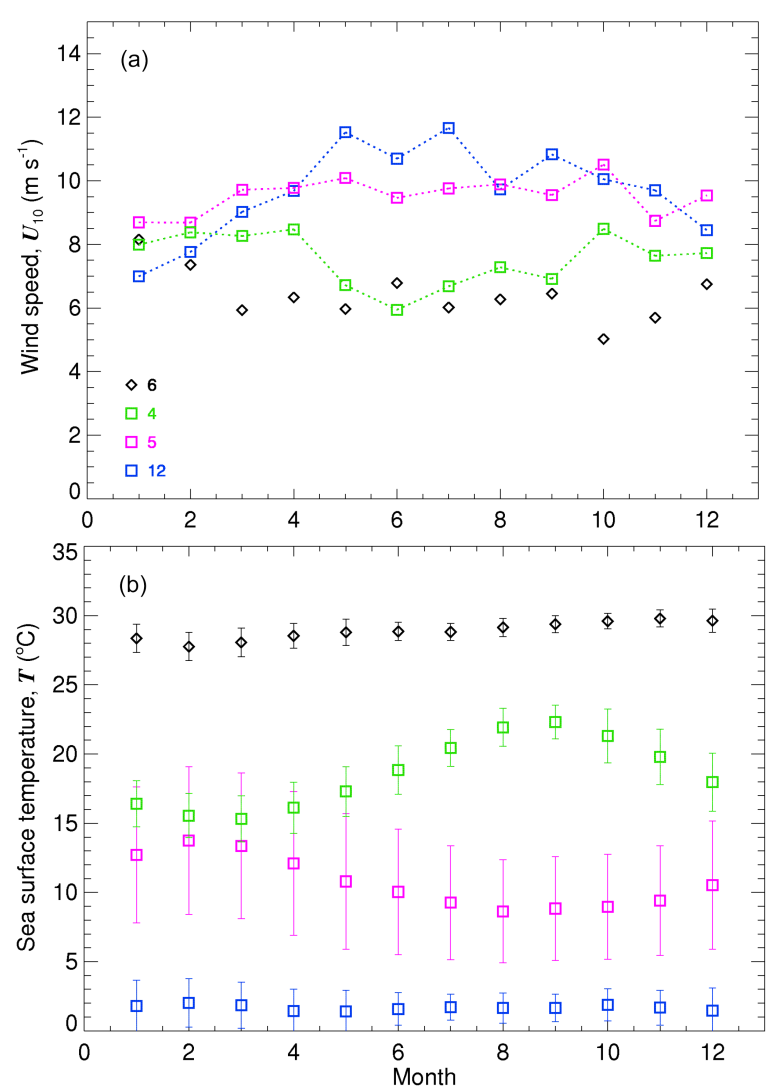

Figure 3. Seasonal cycle for 2006 in different regions as defined in Fig. 2 and Table 1: (a) wind speed $U_{10}$; (b) sea surface temperature (SST) $T$. The SST error bars in (b) are \pm 1 standard deviation; the $U_{10}$ error bars are wider and not plotted in (a) for clarity. The regions represent: 4 - temperate zone in the Northern Hemisphere; 5 - temperate zone in Southern Hemisphere; 6 -doldrums along the Equator; 12 - lowest SST.

gions cover the full range of global oceanic conditions and, while representative of diverse regional conditions, each one has distinct regional characteristics.

\subsubsection{Independent data source}

Ideally, when deriving a $W\left(U_{10}\right)$ parameterization, the data for $W$ and $U_{10}$ should come from independent sources. The intrinsic correlation between $W$ and $U_{10}$ that might have arisen from the use of $U_{10}$ from QuikSCAT in the estimates of $W$ from $T_{\mathrm{B}}$ (Sect. 2.2.1), might affect the relationship between $W$ and $U_{10}$ developed here. To evaluate the magnitude of such intrinsic correlation, we used $U_{10}$ from the ECMWF ( $\left.U_{10 \mathrm{ECMWF}}\right)$, which is considered to be a more independent source. Note though that even the ECMWF data are generated by assimilating observational data sets (e.g., from buoys) in a coupled atmosphere-wave model (GoddijnMurphy et al., 2011).

To compile this "independent" data set, we made timespace matchups between the $W_{37}$ data and $U_{10 \mathrm{ECMWF}}$ from the 3-hourly ECMWF data for 2006. For each $W-U_{10 \mathrm{QSCAT}}$ pair at a time $t$ from the original $W$ database, there is a corresponding $W-U_{10 \mathrm{ECMWF}}$ pair of data within an interval $t \pm 1.5 \mathrm{~h}$. This matching procedure differs from the $W-U_{10 \mathrm{QSCAT}}$ matching which was done at the WindSat swath resolution, before gridding the variables for the whitecap database (Anguelova et al., 2010). To speed up calculations, and because this already provides a statistically significant amount of data, we used only ascending satellite overpasses. Wind speeds above $35 \mathrm{~m} \mathrm{~s}^{-1}$ were discarded. Besides ECMWF wind data, for consistency we also extracted ECMWF SST values.

Figure 4a shows all ECMWF wind speed data that have been matched in time and space with the available $U_{10 \mathrm{QSCAT}}$ data for March 2006. The majority of the data is clustered in the range of $5-10 \mathrm{~m} \mathrm{~s}^{-1}$ (dark red). To characterize the difference between the two wind speed sources, the correlation between $U_{10}$ from ECMWF and $U_{10}$ from QuikSCAT was determined as the best linear fit forced through zero

$U_{10 \mathrm{ECMWF}}=0.953 U_{10 \mathrm{QSCAT}}$,

with a coefficient of determination $R^{2}=0.824$. For comparison, the unconstrained fit between $U_{10 \mathrm{QSCAT}}$ and $U_{10 \mathrm{ECMWF}}$ is also shown in Fig. 4a (dashed line); both fits are very close (they almost overlap) with identical correlation coefficients $\left(R^{2}=0.824\right.$ for the unconstrained fit). Similarly, Fig. $4 \mathrm{~b}$ compares $T$ from ECMWF and GDAS showing almost $1: 1$ correlation. That is, the two data sources provide almost the same values for $T$.

On average, $U_{10}$ from ECMWF is about $5 \%$ lower than $U_{10}$ from QuikSCAT. This $U_{10}$ difference can be explained to some extent with the effect of atmospheric stability because QuikSCAT provides equivalent neutral wind which accounts for the stability effects on the wind profile (Kara et al., 2008; Paget et al., 2015), while the ECMWF model gives stabilitydependent wind speeds (Chelton and Freilich, 2005).

Having the correlation between $U_{10}$ from the whitecap database and $U_{10}$ from the ECMWF quantified (as well as for $T$ ), one can evaluate differences caused by the use of different data sources. Equation (7) could also be useful when one decides to use ECMWF data because of their availability at 6 or $3 \mathrm{~h}$ intervals as compared to the availability of $W, U_{10}$, and $T$ matchups twice a day (Sect. 2.2.1).

\subsection{Implementation}

We aim to develop an expression capable of modeling both the trend of the satellite-based $W$ data with $U_{10}$ and their spread (see green and magenta symbols in Fig. 1b).

\subsubsection{Adjusting the wind speed exponent}

We first analyze the satellite-based $W$ data to derive a general $W\left(U_{10}\right)$ expression (i.e., the trend of $W$ with $\left.U_{10}\right)$. We apply Eq. (6) with coefficients $(n, a, b)$ left as free parame- 
Table 2. Regression coefficients $n, a$, and $b$ with $95 \%$ CIs derived as free parameters from fitting Eq. (6) to different global data sets.

\begin{tabular}{lrrr}
\hline Data set & $n \pm 95 \% \mathrm{CI}$ & $a \pm 95 \% \mathrm{CI}$ & $b \pm 95 \%$ CI \\
\hline$W_{10}$ & $2.22 \pm 3.23 \times 10^{-7}$ & $5.23 \times 10^{-5} \pm 5.73 \times 10^{-11}$ & $-0.226 \pm 1.54 \times 10^{-6}$ \\
$W_{37}$ & $1.46 \pm 6.15 \times 10^{-7}$ & $6.17 \times 10^{-4} \pm 1.21 \times 10^{-9}$ & $-0.957 \pm 3.58 \times 10^{-6}$ \\
$W_{10}$ and $W_{37}$ & $1.79 \pm 8.10 \times 10^{-7}$ & $2.03 \times 10^{-4} \pm 5.43 \times 10^{-10}$ & $-0.409 \pm 4.36 \times 10^{-6}$ \\
\hline
\end{tabular}
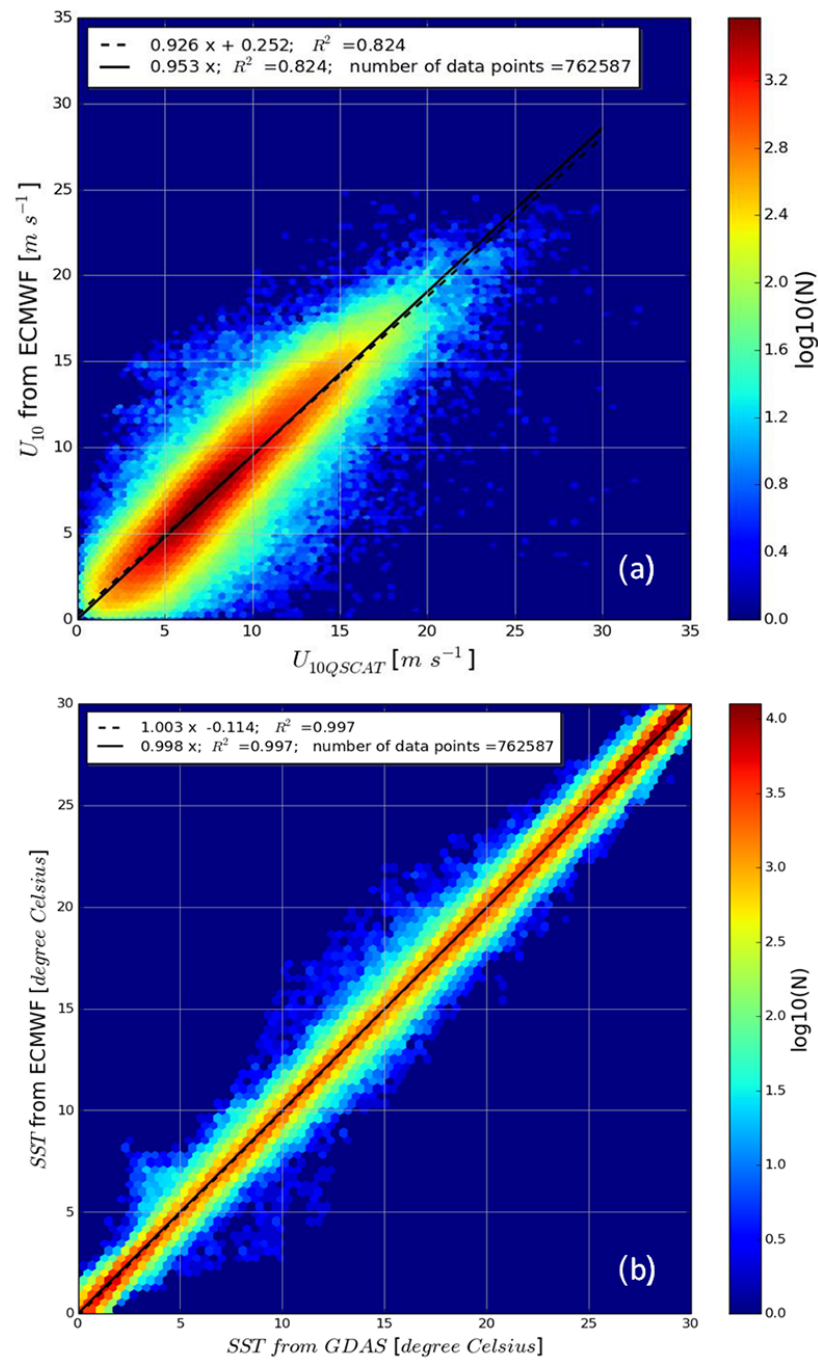

Figure 4. Scatter plot for March 2006 of (a) global $U_{10 \mathrm{ECMWF}}$ vs. $U_{10 \mathrm{QSCAT}}$ and (b) global $T$ from ECMWF vs. $T$ from GDAS. In both figures the colors indicate the amount of data points per hexbin. The black lines are linear fits: the dashed line represents unrestricted fit and the solid line a fit forced through zero. The linear regressions and respective $R^{2}$ are listed in each panel.

ters to global data sets of $W_{10}, W_{37}$, and both together $\left(W_{10}\right.$ and $\left.W_{37}\right)$. Table 2 shows the results for the regression coefficients determined from the fitting procedure within the $95 \%$ CI. Each set of coefficients $(n, a, b)$ accounts implicitly for $U_{10}$ and all secondary factors.
To consistently interpret and explicitly quantify regional and seasonal variations of $W$ data, it is necessary to analyze all $W$ data - global, regional, and at different frequencies - with the same mean trend given by the $W\left(U_{10}\right)$ expression. Because Table 2 shows different wind speed exponents, we need to establish a general (unifying) $n$ value. With sampling uncertainty removed from the determination of these $n$ values (see the $95 \%$ CIs in Table 2), we now investigate the variations of the wind speed exponents among data sets. The mean of the free-parameter $n$ values in Table 2 is 1.82 with lower and upper limits of the $95 \%$ CI of 0.88 and 2.77. A value of $n=2$ is within this $95 \% \mathrm{CI}$ and is thus a reasonable choice for such general (unifying) wind speed exponent. We further verified such a choice by applying two-sample $t$ test for equal means to the $n$ values in Table 2 and $n=2$. The $t$ test showed that the mean of the wind speed exponents $n$ determined as free parameters is not statistically different from $n=2(p>0.05)$. On this ground, we adjust the freeparameter wind speed exponents to $n=2$, a quadratic wind speed dependence of $W$.

Quadratic wind speed dependence here is not unprecedented. The first reported $W\left(U_{10}\right)$ relationship of Blanchard (1963) was quadratic. With careful statistical considerations, Bondur and Sharkov (1982) derived a quadratic $W\left(U_{10}\right)$ relationship for residual $W$ (strip-like structures, in their terminology). Parameterizations of $W$ in waters with different SST have also resulted in wind speed exponents around 2 (see Table 1 in Anguelova and Webster, 2006). Quadratic wind speed dependence is also consistent with the wind speed exponents of SAL13 in Eq. (1).

With the adjustment of the free-parameter $n$ in Eq. (6) to a general (unifying) wind speed exponent $n=2$, for all subsequent analyses, we use a functional form for $W\left(U_{10}\right)$ modified from Eq. (6) to

$W=a\left(U_{10}+b\right)^{2}$.

Following Monahan and Lu (1990), we derive an expression $W\left(U_{10}\right)$ in the form of Eq. (8a) by plotting $W^{1 / 2}$ as a function of $U_{10 \mathrm{QSCAT}}$. Applying linear regression, we find an expression:

$W^{1 / 2}=m U_{10}+c$,

which is then rearranged and squared to provide coefficients $a=m^{2}$ and $b=c / m$ in Eq. (8a) (results in Sect. 3.1.1). All linear fits are done on the $W$ data associated with $U_{10}$ from 3 
to $20 \mathrm{~m} \mathrm{~s}^{-1}$. The lower limit of $3 \mathrm{~m} \mathrm{~s}^{-1}$ is chosen as a threshold for observing whitecaps. This restriction is reasonable in light of the SAL13 analysis in which $W$ data with a relative standard deviation $\left(\sigma_{W} / W\right)>2$ were removed: the discarded $W$ data were about $10 \%$ of all $W$ data, mostly in regions with low wind speeds of around $3 \mathrm{~m} \mathrm{~s}^{-1}$. We exclude the high wind speed regime in order to avoid uncertainty due to (i) fewer data points in this regime; and (ii) anticipated larger uncertainty in the $W$ data from the $W\left(T_{\mathrm{B}}\right)$ algorithm.

\subsubsection{Intrinsic correlation analysis}

For the intrinsic correlation analysis, the $W-U_{10 \mathrm{ECMWF}}$ data pairs are used in a similar fashion to make $W^{1 / 2}\left(U_{10 \mathrm{ECMWF}}\right)$ linear fits and derive from them a relationship between the satellite-based $W$ data and the ECMWF wind speeds. The two global $W\left(U_{10}\right)$ parameterizations for the two wind speed sources are then compared to evaluate the magnitude of the intrinsic correlation (results in Sect. 3.1.2).

Because Fig. 4 and Eq. (7) give the possibility to evaluate discrepancies due to the use of different sources for $U_{10}$ and $T$, we use $U_{10}$ and $T$ from the whitecap database in all subsequent analyses and results. In this way, with the intrinsic correlation characterized, we restrict the uncertainty in our analyses by using the close matching up of $W, U_{10}$, and $T$ data in the whitecap database. This decision is reasonable considering that both data sets can be used in practice for different applications. The collocated data in the whitecap database (involving QuikSCAT) are most suitable for analysis (as done in this study). Meanwhile, $W$ data from the whitecap database combined with forcing data from a global model (such as ECMWF or other) are useful for forecasts and climate simulations.

\subsubsection{Regional analysis}

With $n=2$ for the general wind speed dependence determined, we then apply Eq. (8b) to the regional monthly subsets of $W_{10}$ and $W_{37}$ data. All available data per month were used, ranging from 22 to 31 days of data. Once again, scatter plots of $W^{1 / 2}\left(U_{10}\right)$ were generated and the best linear fits were determined providing coefficients $m$ and $c$ for each region for each month for $W_{10}$ and $W_{37}$. The regional and seasonal variations of coefficients $a$ and $b$ are analyzed to inform us how to parameterize them in terms of SST, i.e., obtain $a(T)$ and $b(T)$ (results in Sect. 3.2).

To quantify how $a(T)$ and $b(T)$ are influenced by different wind speed dependences - our empirically determined (adjusted) wind speed exponent $n=2$ (Eq. 8a) or the physically reasoned cubic wind speed dependence (Eq. 5b) - we also analyzed scatter plots of $W^{1 / 3}\left(U_{10}\right)$ and derived a respective set of coefficients $a(T)$ and $b(T)$.

We quantify differences between new and previously published parameterizations with two metrics (results in Sect. 3.3): (i) the PD between $W$ values obtained with dif- ferent parameterizations; and (ii) significance tests (Student $t$ test and ANOVA) of the differences between $W$ values obtained with new and previous $W$ parameterizations.

\subsubsection{Wave field analysis}

Efforts to include wave parameters in $W$ parameterizations are well justified because, after wind speed, the most important secondary factor that accounts for variability in $W$ is the wave field (SAL13). Lacking wave characteristics, the early version of the whitecap database is not suitable for deriving an explicit expression for the wave field influence on $W$. However, we have investigated the effect of rising and waning winds on the $W\left(U_{10}\right)$ relationship (results in Sect. 3.1.3); increasing-decreasing winds are considered a proxy for undeveloped-developed seas (Stramska and Petelski, 2003; CAL08).

It is not feasible to determine whether winds are rising or waning from satellite-based wind speed data because of their low temporal resolution (twice a day at a given location). As wind speed provided by ECMWF is available every $3 \mathrm{~h}$, $U_{10 \mathrm{ECMWF}}$ values were used to examine the wind conditions at the satellite overpass time associated with a $W$ data point. Wind speed difference between two $3 \mathrm{~h}$ intervals $\Delta U_{10}$ has been used to detect changing winds. Wind speed differences of $\Delta U_{10}$ from 1 to $5 \mathrm{~m} \mathrm{~s}^{-1}$ in steps of $1 \mathrm{~m} \mathrm{~s}^{-1}$ were used to examine the sensitivity of the analysis to the choice of $\Delta U_{10}$ in identifying rising or waning winds. Higher $\Delta U_{10}$ values are associated with the passage of stronger atmospheric lowpressure systems, which come with higher wind speeds and thus stronger wind forcing of waves. The $U_{10 \mathrm{QSCAT}}$ values were correlated with $W$ using Eq. (8). Only data for $37 \mathrm{GHz}$ from the ascending satellite overpass were used.

\subsection{Estimation of sea spray aerosol emissions}

The newly formulated $W\left(U_{10}, T\right)$ parameterization is applied to estimate the global annual SSA emission using the SSSF of M86 (Eq. 4). Dividing Eq. (4) by Eq. (3), we modify the M86 SSSF to clearly separate the magnitude and shape factors (rewritten here as Eq. $4^{\prime}$ ):

$$
\begin{aligned}
& \frac{\mathrm{d} F}{\mathrm{~d} r_{80}}=W\left(U_{10}\right)\left[\frac{1}{\tau} \frac{\mathrm{d} E}{\mathrm{~d} r_{80}}\right]=W\left(U_{10}\right) \\
& \cdot\left[3.5755 \times 10^{5} \cdot r_{80}^{-3}\left(1+0.057 r_{80}^{1.05}\right) \times 10^{1.19 e^{-B^{2}}}\right]
\end{aligned}
$$

with $B$ as defined in Sect. 1. While Eq. (4') shows that the timescale $\tau$ is distinct from the shape factor $\mathrm{d} E / \mathrm{d} r$, for the calculations the value of $\tau$ is included in the numerical coefficient in the brackets. The size range for M86 validity is $r_{80}=0.8-8 \mu \mathrm{m}$. We calculate the SSA flux for radii $r_{80}$ ranging from 1 to $10 \mu \mathrm{m}$. Refer to Anguelova (2016) for using the $W\left(U_{10}\right)$ parameterization of SAL13 to estimate $\mathrm{CO}_{2}$ transfer velocity and SSA flux for $r_{80}$ ranging from 0.4 to $250 \mu \mathrm{m}$. 


\subsubsection{Use of the discrete whitecap method}

The main assumptions of M86 for the SSSF based on the discrete whitecap method - constant values for $\tau$ and $\mathrm{d} E / \mathrm{d} r$ (Sect. 1) - are usually questioned (Lewis and Schwartz, 2004; de Leeuw et al., 2011; Savelyev et al., 2014). It is not expected for either of these assumptions to hold for wave breaking at various scales and under different conditions in different locations. The SSSF proposed by Smith et al. (1993) on the basis of measured size-dependent aerosol concentrations is one of the first formulations to demonstrate that the shape factor cannot be constant. Norris et al. (2013a) also demonstrated that the aerosol flux per unit area whitecap varies with the wind and wave conditions.

Recently, Callaghan (2013) showed that the whitecap timescale is another source of often overlooked variability in SSSF parameterizations based on M86. Because $W$ typically includes foam from all stages of whitecap evolution, Callaghan (2013) suggested that the adequate timescale for the aerosol productivity from a discrete whitecap is not just its decay time (as in Eqs. 4 and $4^{\prime}$ ), but the sum of the whitecap formation and decay timescales $\tau^{\prime}$. The value of $\tau^{\prime}$ varies from breaking wave to breaking wave, but an area-weighted mean whitecap lifetime can be calculated for any given observational period to account for this natural variability. Analyzing the lifetimes of 552 oceanic whitecaps from a field experiment, Callaghan (2013) found that the area-weighted mean $\tau^{\prime}$ varies by a factor of 2.7 (from 2.2 to $5.9 \mathrm{~s}$ ). We refer the reader to Callaghan (2013) for an SSSF that accounts for SSA flux variability by explicitly incorporating whitecap timescale $\tau^{\prime}$.

Despite these questionable assumptions, the SSSF based on the discrete whitecap method in the form of M86 has been widely used in many models (Textor et al., 2006). Therefore, to those who have worked with M86 until now, a meaningful way to demonstrate how the new satellite-based $W$ data, and $W$ parameterizations based on them, would affect estimates of SSA flux is to hold everything else constant (e.g., the whitecap timescale and productivity in the shape factor) and clearly show differences caused solely by the use of new $W$ expression(s) as a magnitude factor. On these grounds, the choice of the SSSF based on the M86 whitecap method is a suitable baseline for comparisons.

\subsubsection{Choice of size distribution}

Though the chosen size range of $1-10 \mu \mathrm{m}$ for SSA particles is limited, it is well justified for the purposes of this study with the following arguments.

Generally, the division of the SSA particles into sizes of small, medium, and large modes (de Leeuw et al., 2011, their Sect. 8) is well warranted when one considers the climatic effect to be studied (Sect. 1). For example, submicron particles are important for scattering by SSAs (direct effect) and the formation of cloud condensation nuclei (indirect effect), while super-micron particles are important for heat exchange (via sensible and latent heat fluxes) and heterogeneous chemical reactions (which need surface and volume to proceed effectively). However, in this study we do not focus on how the choice of the size distribution will affect the SSA estimates, nor do we aim to present estimates of specific effect on the climate system. Rather, with a fixed size distribution, we explore how parameterizing $W$ data, which carry information for the influences of many factors, would affect estimates of SSA emission (Sect. 1). In this sense, we can choose to use any published size distribution as a shape factor.

The chosen size range is the range of medium (supermicron) mode of SSA particles. The size distribution of M86 is valid within this range (Sect. 2.4). The M86 size distribution, in its original or modified form, is widely used in GCMs and CTMs (Textor et al., 2006, their Table 3). The size range of $1-10 \mu \mathrm{m}$ is a recurrent part of the various size ranges used in all (or at least most) SSSFs (see Table 2 in Grythe et al., 2014; hereafter G14).

The chemical composition of the SSA particles is another argument favoring the chosen size range. The super-micron particles consist, to a good approximation, solely of sea salt, whereas in biologically active regions, the submicron size range additionally includes organic material, with an increasing contribution as particle size decreases (O'Dowd et al., 2004; Facchini et al., 2008; Partanen et al., 2014). Since the organic mass fraction in submicron SSA particles is still highly uncertain (Albert et al., 2012), we focus on the medium-mode SSA emissions.

We evaluate the discrepancy expected due to neglecting particles below $1 \mu \mathrm{m}$ using the G14 report of SSA production rate for dry particle diameters $D_{\mathrm{p}}=r_{80}$ obtained with M86 over two different size ranges: $4.51 \times 10^{12} \mathrm{~kg} \mathrm{year}^{-1}$ for the size range of $0.8 \mu \mathrm{m}<r_{80}<8 \mu \mathrm{m}$ and $5.20 \times 10^{12} \mathrm{~kg}$ year $^{-1}$ for size range of $0.1 \mu \mathrm{m}<r_{80}<10 \mu \mathrm{m}$. The different size ranges bring a difference between the two G14 estimates of about $14 \%$. Neglecting particles with $r_{80}<0.1 \mu \mathrm{m}$ would not significantly change the results presented here because they contribute on the order of $1 \%$ to the overall mass (Facchini et al., 2008).

Because total whitecap fraction, rather than only the active breaking crests, provides bubble-mediated production of SSAs, we use $W_{37}$ data to estimate the emission of mediummode SSAs. The calculations use a modeling tool (Albert et al., 2010) in which the $W\left(U_{10}\right)$ parameterization of MOM80, as incorporated in Eq. (4), was replaced with the newly derived $W\left(U_{10}, T\right)$ parameterization (Eq. $\left.4^{\prime}\right)$. The resulting size-segregated droplet number emission rate was converted to mass emission rate using the approximation $r_{80}=2 r_{\mathrm{d}} \equiv$ $D_{\mathrm{p}}$, where $r_{\mathrm{d}}$ and $D_{\mathrm{p}}$ are the particle dry radius and diameter, respectively (e.g., Lewis and Schwartz, 2004; de Leeuw et al., 2011), and a density of dry sea salt of $2.165 \mathrm{~kg} \mathrm{~m}^{-3}$. 

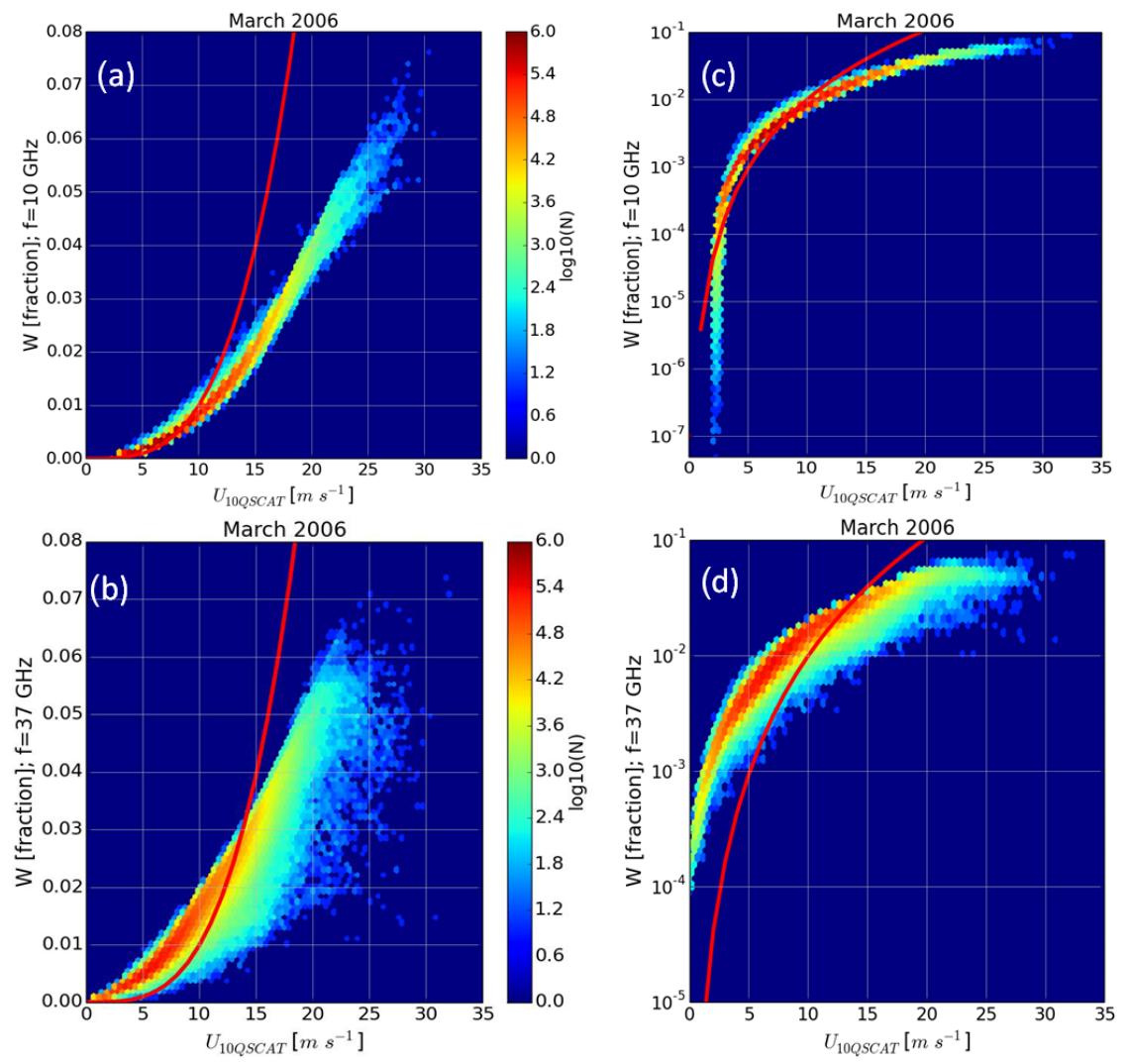

Figure 5. Global $W$ as a function of $U_{10}$ from QuikSCAT for March 2006 where $W$ is obtained with $10 \mathrm{GHz}$ (a) and $37 \mathrm{GHz}$ (b) measurement frequency. Panels (c) and (d) plot the data in (a) and (b) with logarithmic y axis. The red line indicates the Monahan and O’Muircheartaigh (1980, MOM80) relationship (Eq. 3). The colors indicate the amount of data points per hexbin.

\section{Results and discussion}

The graphs visualizing our results use all $W$ data available for wind speeds from 0 to $35 \mathrm{~m} \mathrm{~s}^{-1}$. This range of $U_{10}$ is beyond the range $3 \leq U_{10} \leq 20 \mathrm{~m} \mathrm{~s}^{-1}$ used for all fits (Sect. 2.3). In addition, the QuikSCAT instrument, which provided the $U_{10}$ satellite data used in this study, has a decreased sensitivity for wind speeds over $20 \mathrm{~m} \mathrm{~s}^{-1}$ (Quilfen et al., 2007). All results regarding higher wind speeds should, therefore, be used with caution.

\subsection{Global data sets}

Figure 5 shows global $W$ data estimated from WindSat measurements for March 2006 as a function of $U_{10 Q S C A T}$ with linear and logarithmic $y$ axes at $10 \mathrm{GHz}$ (Fig. 5a and c) and $37 \mathrm{GHz}$ (Fig. 5b and d). For comparison, the MOM80 relationship (Eq. 3) is also plotted in each panel (red curves). There are three noteworthy observations in Fig. 5. First, we note the different variability of $W_{10}$ and $W_{37}$ data. The $10 \mathrm{GHz}$ data show far less variability than those at $37 \mathrm{GHz}$. The $W_{37}$ data at a certain wind speed vary over a much wider range, with the strongest variability for wind speeds of 10$20 \mathrm{~m} \mathrm{~s}^{-1}$. This observation confirms similar observation re- ported and analyzed at length by SAL13 in terms of other variables, in addition to $U_{10}$, which influence the whitecap fraction, such as SST, wave field, etc. While SAL13 analyzed this variability, we investigate how well this variability can be parameterized in terms of available secondary variables, SST in our case.

Another observation in Fig. 5 is noted at low wind speeds. The $10 \mathrm{GHz}$ scatter plots do not show $W$ data for wind speeds lower than about $2 \mathrm{~m} \mathrm{~s}^{-1}$ because at these low wind speeds no active breaking occurs (Sect. 1). In contrast, non-zero $W_{37}$ data are estimated at wind speeds $U_{10}<2 \mathrm{~m} \mathrm{~s}^{-1}$. Salisbury et al. (2013) suggested that the presence of foam on the ocean surface at these low wind speeds could be due to residual long-lived foam. This residual foam might be stabilized by surfactants, which increases its lifetime (Garrett, 1967; Callaghan et al., 2013). Another explanation could be production of bubbles and foam from biological activity (Medwin, 1977). However, there is not enough information currently to prove any of these conjectures.

The comparison of the MOM80 relationship (Eq. 3) to $W_{10}$ and $W_{37}$ data clearly reveals the most important feature in Fig. 5 - the wind speed dependence of satellite-based $W$ data deviates from cubic and cubic-like relationships. 


\subsubsection{Wind speed dependence}

Following the arguments of our approach (Sect. 2.1) and evaluating the wind speed exponents determined as free parameters (Sect. 2.3.1), we found that a quadratic wind speed exponent $(n=2)$ fits reasonably well both $W_{10}$ and $W_{37}$ data sets. For the same data shown in Fig. 5, Fig. 6 shows the linear regression of the square root of $W$ vs. $U_{10}$ :

$$
\begin{array}{ll}
W^{1 / 2}=10.23 \times 10^{-3} U_{10}-10.82 \times 10^{-3} & 10 \mathrm{GHz} \\
W^{1 / 2}=10.38 \times 10^{-3} U_{10}+18.57 \times 10^{-3} & 37 \mathrm{GHz}
\end{array}
$$

with coefficients of determination $R^{2}$ of 0.996 and 0.951 , respectively. From Eq. (9), we obtain the following global average wind speed dependence of $W$ using $U_{10}$ from QuikSCAT:

$$
\begin{aligned}
& W_{10}=10.47 \times 10^{-5}\left(U_{10}-1.058\right)^{2} \\
& W_{37}=10.77 \times 10^{-5}\left(U_{10}+1.789\right)^{2},
\end{aligned}
$$

where $W$ is a fraction (not a percentage).

Figure 6c compares $W\left(U_{10}\right)$ in Eqs. (10)-(11) to $W\left(U_{10}\right)$ of SAL13. The trends are close, implying that having a different wind speed exponent is largely balanced by corresponding changes to the parametric coefficients. Indeed, the PD between our quadratic $W\left(U_{10}\right)$ and SAL13 $W\left(U_{10}\right)$ at $37 \mathrm{GHz}$ ranges from 0.5 to $10 \%$ over the wind speed range of 3-20 $\mathrm{m} \mathrm{s}^{-1}$. ANOVA and Student tests show that these differences are not statistically significant. That is, the global quadratic $W\left(U_{10}\right)$ parameterization approaches the predictions of the SAL13 parameterization, which has a more specific wind speed exponent $(n=1.59)$. Note that we do not expect our $W\left(U_{10}\right)$ parameterization to be distinctly different from that of SAL13 because both studies use the same data for $W$ and $U_{10}$ (though from different versions of the whitecap database). Rather, we aim to identify a general $W\left(U_{10}\right)$ trend in order to perform consistent regional analysis.

The $y$ intercept for $W_{10}$ (Eq. 10) is negative and, following the usual interpretation, yields a threshold wind speed of about $1.1 \mathrm{~m} \mathrm{~s}^{-1}$ for whitecap inception. This is in the range of previously published values from 0.6 (Reising et al., 2002) to 6.33 (Stramska and Petelski, 2003). Meanwhile, the positive $y$ intercept $b$ for $W_{37}$ (Eq. 11) is meaningless at first glance and intriguing upon some pondering. While stabilized residual foam and/or foam from biological sources are possible (Sect. 3.1), it is not known whether such mechanisms are capable of providing a measurable amount of foam patches which produce bubble-mediated sea spray efficiently.

We propose broader interpretation of $b$ in Eqs. (10)-(11), be it negative or positive. Generally, it is expected that the atmospheric stability (Kara et al., 2008) and fetch (through the wave growth and development) cause inception of the whitecaps at lower or higher wind speed. One can consider the range of values for $b$ mentioned above ( 0.6 to 6.33$)$ as an expression of such influences. We suppose that $b$ can also
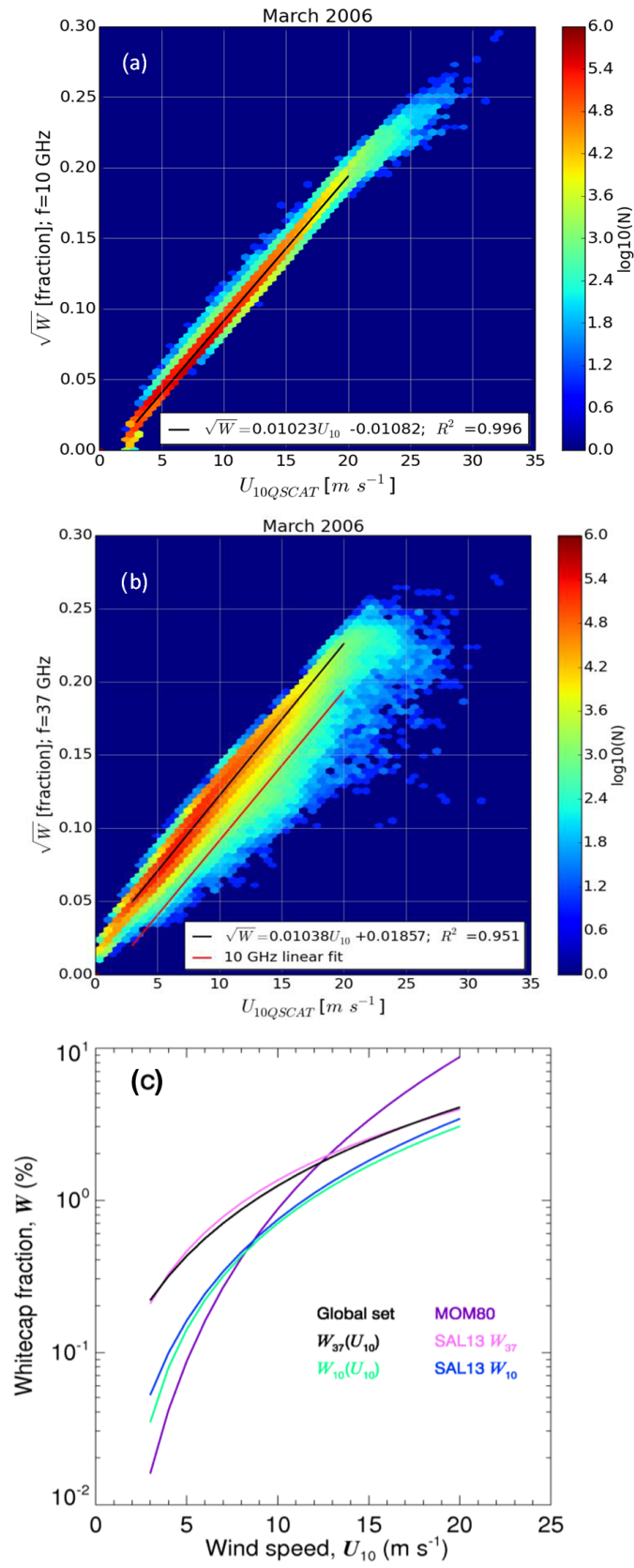

Figure 6. Wind speed dependence of whitecap fraction $W\left(U_{10}\right)$ derived from the global $W$ data set: (a) $W^{1 / 2}$ as a function of $U_{10}$ from QuikSCAT for March 2006, where $W^{1 / 2}$ is obtained with $10 \mathrm{GHz}$ measurement frequency; (b) same as in (a) but for $37 \mathrm{GHz}$. The black line in both panels indicates the best linear fit through the data. The red line in (b) equals the black line in (a). The colors indicate the amount of data points per hexbin. (c) Comparison of derived global $W\left(U_{10}\right)$ at $10 \mathrm{GHz}$ (green line) and $37 \mathrm{GHz}$ (black line) to $W\left(U_{10}\right)$ parameterizations of Salisbury et al. (2013) in Eq. (1) for $10 \mathrm{GHz}$ (blue line) and $37 \mathrm{GHz}$ (magenta). Parameterization $W\left(U_{10}\right)$ of Monahan and O'Muircheartaigh (1980, MOM80) in Eq. (3) (purple line) is shown for reference. 
incorporate the effect of the seawater properties on the extent of $W$. The net result of all secondary factors may be either negative or positive $b$.

Specifically, we promote the hypothesis that a positive $y$ intercept $b$ can be interpreted as a measure of the capacity of seawater with specific characteristics, such as viscosity and surface tension - which are governed by SST, salinity, and surfactant concentration - to affect $W$. Undoubtedly, none of these secondary factors creates whitecaps per se. Rather, they prolong or shorten the lifetime of the whitecaps via processes governed by the seawater properties. For instance, surfactants and salinity influence the persistence of submerged and surface bubbles. This yields variations of bubble rise velocity that replenish the foam on the surface at different rates. Long-lived decaying foam added to foamy areas created by subsequent breaking events would augment $W$; conversely, conditions that shorten bubble lifetimes would reduce $W$ (or at least not add to $W$ ).

A positive $y$ intercept can be thought of as a mathematical expression of this static forcing (as opposed to dynamic forcing from the wind) that given seawater properties can sustain. That is, at any given location, this static forcing acts as though higher wind speed of magnitude $\left(U_{10}+b\right)$ is producing more whitecaps than $U_{10}$ alone. By parameterizing coefficients $a$ and $b$ in terms of different variables, one can evaluate how much the static forcing affects $W$ in different geographic regions. By developing parameterizations $a(T)$ and $b(T)$ (Sect. 2.1), here we quantify only one static influence.

\subsubsection{Intrinsic correlation}

To quantify the possible intrinsic correlation in the derived $W\left(U_{10}\right)$ parameterization (Eqs. $\left.10-11\right)$, we derived $W\left(U_{10}\right)$ using ECMWF wind speeds instead of the QuikSCAT wind speeds (Sect. 2.3.2). Figure 7a shows a scatter plot of $W^{1 / 2}$ vs. $U_{10 \mathrm{ECMWF}}$ (only data for $37 \mathrm{GHz}$ are shown); dashed and solid lines show unconstrained and zero-forced fits, respectively. The linear regression (given in the figure legend) is used to obtain the global average wind speed dependence using $U_{10}$ from ECMWF as follows:

$W_{37}=8.1 \times 10^{-5}\left(U_{10}+3.33\right)^{2}$.

The positive intercept here is interpreted as in Sect. 3.1.1. Using Eq. (12), parameterized $W$ values are plotted as a function of $U_{10 \mathrm{ECMWF}}$ in Fig. $7 \mathrm{~b}$. Increased scatter of the $W$ data is evident when comparing Figs. $7 \mathrm{~b}$ and $5 \mathrm{~d}$. We use different metrics to detect and evaluate possible intrinsic correlation.

The change of the coefficient of determination $R^{2}$ of the $W\left(U_{10}\right)$ relationship when QuikSCAT winds are substituted with the ECMWF winds is one sign for the presence of intrinsic correlation. Physically, we expect a strong correlation between $W$ and $U_{10}$, and we see this clearly in Fig. 6b which shows $R^{2}=0.951$ for $W^{1 / 2}$ and $U_{10 \mathrm{QSCAT}}$. However, the correlation coefficient might not be as high as in Fig. 6 if
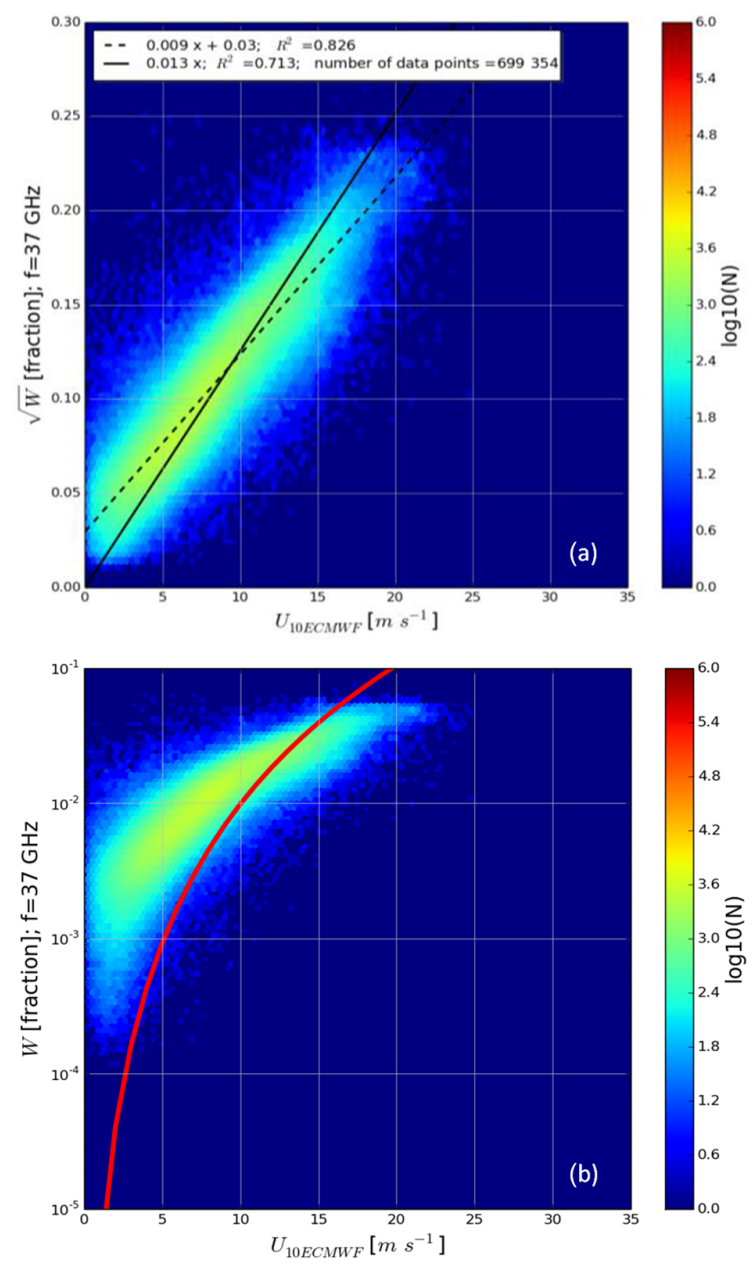

Figure 7. Scatter plots of $W$ data for $37 \mathrm{GHz}$ vs. $U_{10 \mathrm{ECMWF}}$ for March 2006: (a) $W^{1 / 2}$; (b) $W$ obtained with Eq. (12). The black lines in panel (a) are linear fits: the dashed line represents unrestricted fit and the solid line is a fit forced through zero. The linear fits and respective $R^{2}$ are listed. The red line in (b) indicates the Monahan and O'Muircheartaigh (1980, MOM80) relationship (Eq. 3). The colors indicate the amount of data points per hexbin.

$U_{10}$ were from a more independent source. We see this when comparing Figs. $6 \mathrm{~b}$ and $7 \mathrm{a}$. The $W^{1 / 2}-U_{10}$ correlation is still strong in Fig. $7 \mathrm{a}$, but the plot shows more scatter and slightly lower correlation with $R^{2}=0.826$.

Figure 8 visualizes the change in the spread of the $W$ data with a plot of the residuals (biases) between the $W$ data and the derived $W$ parameterizations (Eqs. 11 and 12) as a function of wind speed; Fig. 8a is for $U_{10 \mathrm{QSCAT}}$ and Fig. $8 \mathrm{~b}$ is for $U_{10 \mathrm{ECMWF}}$. Larger biases are evident when $U_{10 \mathrm{ECMWF}}$ is used. The rms deviation between $W$ data and parameterized $W$ values increases from $\Delta W=0.214 \%$ for the data set using $U_{10 \mathrm{QSCAT}}$ to $\Delta W=0.367 \%$ for the data set using $U_{10 \text { ECMWF. }}$

The slopes in Figs. $6 \mathrm{~b}$ and $7 \mathrm{a}$ differ by about $14 \%$. We evaluate how this translates into differences in $W_{37}$ values 

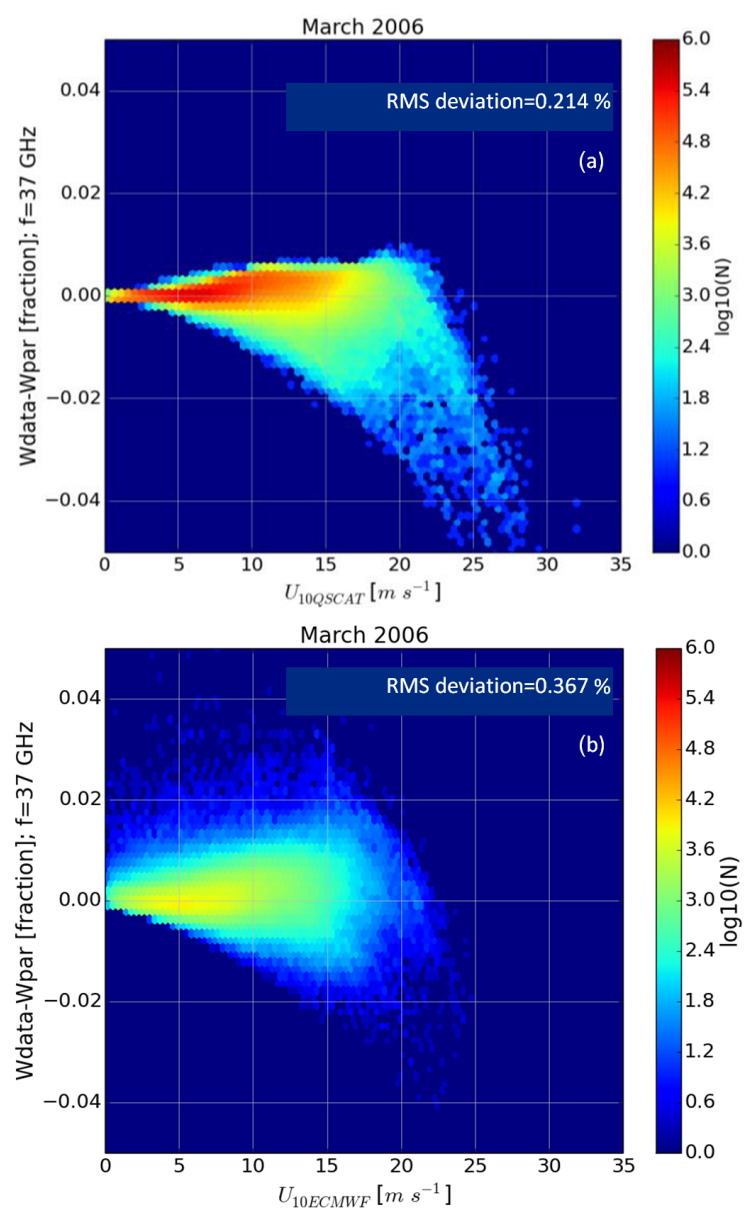

Figure 8. Scatter plots of residuals $\Delta W$ between $W$ data for $37 \mathrm{GHz}$ from the whitecap database and parameterized $W$ values as a function of wind speed from different sources: (a) wind speed values $U_{10 Q S C A T}$ from the whitecap database used with Eq. (11); (b) wind speed values $U_{10 \mathrm{ECMWF}}$ from the ECMWF model used with Eq. (12). The rms deviation for each data set is given in each panel.

as predicted by Eqs. (11) and (12). We found the PD between $W_{37}\left(U_{10 \mathrm{QSCAT}}\right)$ and $W_{37}\left(U_{10 \mathrm{ECMWF}}\right)$ to be less than $\pm 19 \%$ for wind speeds of $4-20 \mathrm{~m} \mathrm{~s}^{-1}$. Specifically, the $W_{37}$ values obtained with $U_{10 \mathrm{QSCAT}}$ and $U_{10 \mathrm{ECMWF}}$ are approximately equal for wind speed of $8 \mathrm{~m} \mathrm{~s}^{-1}$. Below $8 \mathrm{~m} \mathrm{~s}^{-1}$, $W_{37}\left(U_{10 \mathrm{ECMWF}}\right)$ is higher than $W_{37}\left(U_{10 \mathrm{QSCAT}}\right)$ by up to $18.6 \%$. Above $8 \mathrm{~m} \mathrm{~s}^{-1}, W_{37}\left(U_{10 \text { ECMWF }}\right)$ is smaller than $W_{37}\left(U_{10 \mathrm{QSCAT}}\right)$ by up to $14.8 \%$. The difference goes up to $27 \%$ for wind speeds of $3 \mathrm{~m} \mathrm{~s}^{-1}$.

While different metrics suggest that the intrinsic correlation is present and may contribute to these differences, it is not the only reason for the discrepancies. Different matching procedures (Sect. 2.2.3) and the difference of about $5 \%$ between the $U_{10}$ values from the two different sources (Fig. 4a) also contribute to the $W$ discrepancies from Eqs. (11) and (12). We therefore conclude from the PD values that the ef-
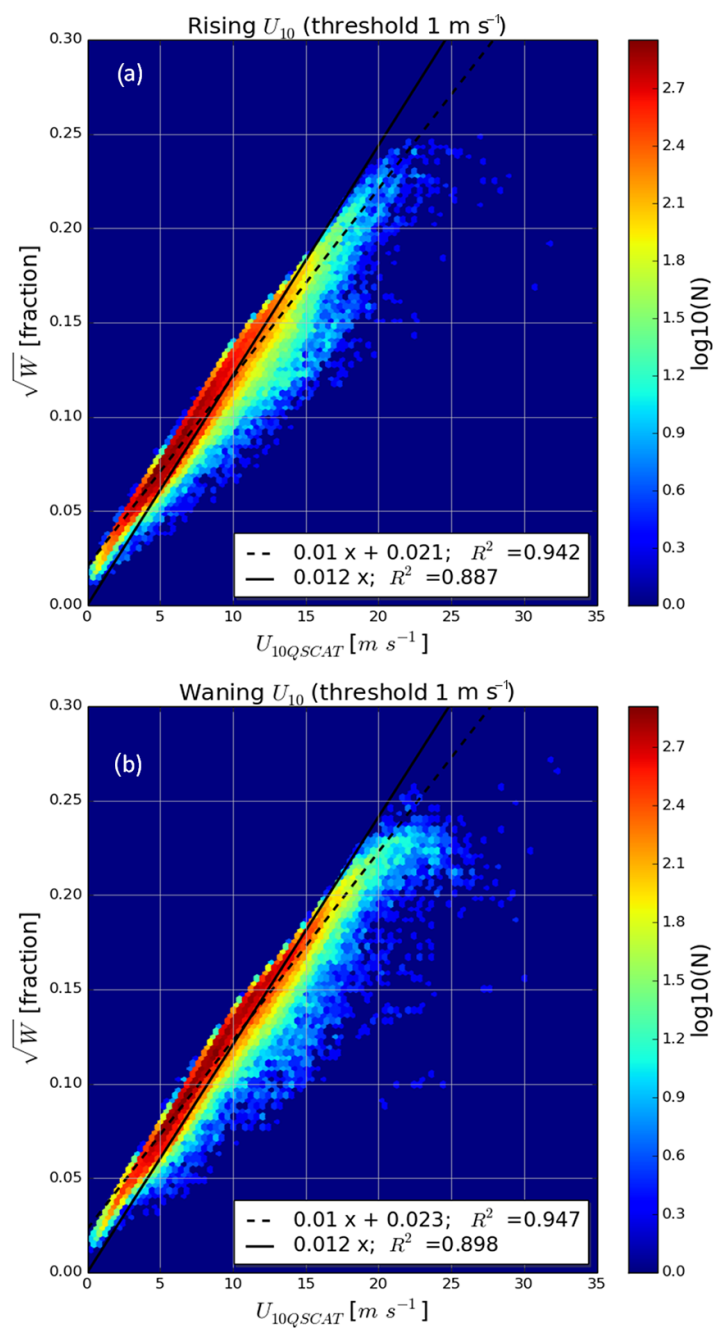

Figure 9. Global $W^{1 / 2}$ for data at $37 \mathrm{GHz}$ as a function of rising (a) and waning (b) $U_{10}$ from QuikSCAT for March 2006. The dashed line indicates the best linear fit through the data, whereas the solid line indicates a linear fit forced through zero.

fect of the intrinsic correlation alone on $W$ is most likely less than about $10 \%$ for most frequently encountered wind speeds.

\subsubsection{Wave field effect}

Figure 9 shows global $W^{1 / 2}$ at $37 \mathrm{GHz}$ as a function of rising and waning $U_{10}$ from QuikSCAT for March 2006; both rising and waning winds were identified with a wind speed difference $\Delta U_{10}=1 \mathrm{~m} \mathrm{~s}^{-1}$ (Sect. 2.3.4). The lines are fits of the data to Eq. (8); solid lines are zero-forced fits. Table 3 shows the slopes $m$ and intercepts $c$ together with $R^{2}$ of the fits for rising and waning winds speeds for $\Delta U_{10}$ from 1 to $5 \mathrm{~m} \mathrm{~s}^{-1}$.

Note the difference between $W^{1 / 2}$ as a function of rising and waning wind speeds in the range of $10-20 \mathrm{~m} \mathrm{~s}^{-1}$ (blue colors): more variability is seen at these wind speeds when 
Table 3. Regression coefficients $m$ (slope) and $c$ (intercept) derived by fitting Eq. (8b) to subsets of $W$ data associated with rising and waning (increasing and decreasing) wind speeds (a proxy analysis for wave field development). Different wind speed differences $\Delta U_{10}$, determined from ECMWF wind speed values, were used to select $W$ data for rising or waning winds. Also given is the coefficient $m$ (slope) for a fit forced though zero (intercept $c=0$ ). Coefficients of determination $R^{2}$ are also given.

\begin{tabular}{|c|c|c|c|c|c|c|c|c|c|c|}
\hline \multirow[t]{2}{*}{$\begin{array}{l}\text { Wind speed } \\
\text { difference } \\
\Delta U_{10}\left(\mathrm{~m} \mathrm{~s}^{-1}\right)\end{array}$} & \multicolumn{2}{|c|}{ Slope $m$} & \multicolumn{2}{|c|}{ Intercept $c$} & \multicolumn{2}{|c|}{$R^{2}$} & \multicolumn{2}{|c|}{$\begin{array}{c}\text { Slope, } m \\
\text { zero intercept }\end{array}$} & \multicolumn{2}{|c|}{$R^{2}$} \\
\hline & Rise & Wane & Rise & Wane & Rise & Wane & Rise & Wane & Rise & Wane \\
\hline 1 & 0.01 & 0.01 & 0.021 & 0.023 & 0.942 & 0.947 & 0.012 & 0.012 & 0.887 & 0.898 \\
\hline 2 & 0.01 & 0.009 & 0.024 & 0.029 & 0.924 & 0.915 & 0.012 & 0.012 & 0.854 & 0.841 \\
\hline 3 & 0.009 & 0.009 & 0.027 & 0.035 & 0.904 & 0.863 & 0.012 & 0.011 & 0.819 & 0.753 \\
\hline 4 & 0.009 & 0.008 & 0.028 & 0.040 & 0.886 & 0.794 & 0.012 & 0.011 & 0.789 & 0.659 \\
\hline 5 & 0.009 & 0.008 & 0.028 & 0.040 & 0.890 & 0.755 & 0.012 & 0.010 & 0.798 & 0.641 \\
\hline
\end{tabular}

the wind is waning than in cases when the wind is rising. Larger variability for waning winds lowers their $R^{2}$ values compared to $R^{2}$ for rising wind speeds for most $\Delta U_{10}$ (Table 3). For both rising and waning wind speeds, $R^{2}$ values decrease with $\Delta U_{10}$ increasing. The reason for this is that higher $\Delta U_{10}$ threshold selects $W^{1 / 2}$ values associated with more extreme wind conditions (Sect. 2.3.4). Because such conditions are rarer, less $W^{1 / 2}$ values are selected yielding an increase in the spread of data points.

Table 3 shows that slopes $m$ for both free and zero-forced fits do not differ substantially for either rising or waning wind speeds for any $\Delta U_{10}$ threshold. The intercepts $c$ of the free fits increase with the wind threshold for both rising and waning winds. The intercepts are larger for waning winds than for rising. These results yield rising-vs.-waning average PD of 10 and $29 \%$ for coefficients $a$ and $b$, respectively.

The rise-wane wind effect, as detected in this study, is not pronounced compared to findings in previous studies that use in situ wind speed data. Goddijn-Murphy et al. (2011) studied wind history and wave development dependencies on in situ $W$ data using wave model (ECMWF), satellite (QuikSCAT), and in situ data for $U_{10}$. These authors detected significant effects only with in situ $U_{10}$. The limited wave field effect in our study might be traced back to the method through which $U_{10}$ was determined: wind speeds from satellites are spatial averages of scatterometric or radiometric observations that take a snapshot of the surface as it is affected by both wind history and wind local conditions, whereas in situ data for wind speed are single-point values averaged over a short time and hence representative of a relatively small area. The effect of the spatial averaging of the satellite data over a much larger area (i.e., the satellite footprint) might be that information on wind history is lost in the process. Limited results on the effect of the wave field obtained with a proxy analysis of the wind history using data paired with a less-than-optimal matching procedure (Sect. 2.2.3) do not justify further consideration in this study.

\subsection{Regional and seasonal data sets}

The wind speed exponent in the $W\left(U_{10}\right)$ relationship derived from the global data set (Eqs. 10-11) implicitly accounts for the globally averaged effects of all secondary factors affecting the satellite-based $W$ data. Now we apply Eq. (8) to regional and seasonal sets of satellite-based $W$ data using this wind speed exponent. We analyze the deviations of the parametric coefficients $a$ and $b$ from the globally averaged trend and parameterize these fluctuations explicitly in terms of SST.

\subsubsection{Magnitude of regional and seasonal variations}

Table 4 exemplifies the results from Eq. (8b): listed are the slopes $m$ and the intercepts $c$ for $W^{1 / 2}-U_{10}$ relationships at 10 and $37 \mathrm{GHz}$ in March 2006 in all 12 regions together with coefficients of determination $R^{2}$ and $95 \%$ CIs from the fitting procedure, as well as mean $U_{10}$ and $T$ values. The results in Table 4 attest that with satellite-based data sets, the sampling uncertainty in determining relationships is removed. The remaining geophysical (i.e., regional and seasonal) variations of coefficients $a$ and $b$, which are obtained from coefficients $m$ and $c$, are investigated here. Figure 10 shows examples of the $W^{1 / 2}$ vs. $U_{10 \mathrm{QSCAT}}$ relationships for different regions and seasons. Figure 10a and b show scatter plots for the Gulf of Mexico (region 1) at both frequencies for January 2006. Statistics are presented in the figure's legend and the fit lines are shown in red. Figure 10c and d show the fit lines $W^{1 / 2}\left(U_{10}\right)$ for 10 and $37 \mathrm{GHz}$ in region 5 for all months, while Fig. 10e and f demonstrate variations of the fit lines $W^{1 / 2}\left(U_{10}\right)$ for both frequencies over all regions for March 2006.

Figure 10 shows that the variations of the $W^{1 / 2}\left(U_{10}\right)$ relationships at $10 \mathrm{GHz}$ are smaller than those for $37 \mathrm{GHz}$. Focusing on the results for $37 \mathrm{GHz}$, we note that geographic differences from region to region for a fixed time period (Fig. 10f) yield more variability in the $W^{1 / 2}\left(U_{10}\right)$ relationship than seasonal variations at a fixed location (Fig. 10d). 
Table 4. Results for slope (coefficient $m$ ) and intercept (coefficient $c$ ) with their $95 \%$ confidential intervals (CI) from Eq. (8b) applied to satellite-based $W$ data for March 2006 for all 12 regions for (a) $10 \mathrm{GHz}$ data; (b) $37 \mathrm{GHz}$ data. Mean wind speed $U_{10}$ and sea surface temperature (SST) $T$ for each region are also given. Such data were obtained for all months.

\begin{tabular}{|c|c|c|c|c|c|c|c|c|}
\hline \multicolumn{9}{|c|}{ (a) $10 \mathrm{GHz}$} \\
\hline Region & Slope $m \times 10^{2}$ & $95 \% \mathrm{CI} \times 10^{8}$ & Intercept $c \times 10^{2}$ & $95 \% \mathrm{CI} \times 10^{7}$ & $R^{2}$ & Mean $U_{10}$ & Mean SST & Samples \\
\hline 1 & 0.983 & 6.47 & -0.766 & 5.05 & 0.995 & 7.4 & 23.7 & 21304 \\
\hline 2 & 0.997 & 0.84 & -0.935 & 0.56 & 0.992 & 6.5 & 26.5 & 208560 \\
\hline 3 & 1.006 & 0.59 & -0.967 & 0.43 & 0.996 & 6.8 & 27.1 & 211152 \\
\hline 4 & 1.027 & 1.98 & -1.077 & 1.77 & 0.996 & 8.2 & 15.3 & 64480 \\
\hline 5 & 1.031 & 0.55 & -1.157 & 0.57 & 0.995 & 9.8 & 13.3 & 268320 \\
\hline 6 & 1.004 & 0.91 & -0.946 & 0.58 & 0.996 & 6.1 & 28.1 & 140064 \\
\hline 7 & 1.005 & 1.30 & -0.937 & 0.96 & 0.995 & 7.0 & 23.9 & 105848 \\
\hline 8 & 1.006 & 2.82 & -0.934 & 1.95 & 0.993 & 6.4 & 27.5 & 58112 \\
\hline 9 & 1.014 & 2.97 & -1.055 & 2.58 & 0.994 & 8.0 & 13.9 & 52952 \\
\hline 10 & 1.021 & 0.85 & -1.091 & 0.80 & 0.995 & 8.8 & 10.6 & 161776 \\
\hline 11 & 1.033 & 3.12 & -1.148 & 3.07 & 0.993 & 9.2 & 11.5 & 55200 \\
\hline 12 & 1.028 & 0.15 & -1.145 & 0.14 & 0.994 & 9.3 & 1.8 & 1039264 \\
\hline \multicolumn{9}{|c|}{ (b) $37 \mathrm{GHz}$} \\
\hline Region & Slope $m \times 10^{2}$ & $95 \% \mathrm{CI} \times 10^{8}$ & Intercept $c \times 10^{2}$ & $95 \% \mathrm{CI} \times 10^{7}$ & $R^{2}$ & Mean $U_{10}$ & Mean SST & Samples \\
\hline 1 & 0.999 & 22.90 & 2.270 & 18.22 & 0.9574 & 7.3949 & 23.7273 & 18056 \\
\hline 2 & 1.088 & 2.67 & 1.391 & 1.772 & 0.9453 & 6.4370 & 26.4630 & 191728 \\
\hline 3 & 1.032 & 2.46 & 1.545 & 1.812 & 0.9518 & 6.6755 & 27.1823 & 185224 \\
\hline 4 & 0.986 & 7.10 & 2.623 & 6.45 & 0.9604 & 8.2645 & 15.3113 & 55216 \\
\hline 5 & 1.002 & 1.68 & 2.413 & 1.751 & 0.9589 & 9.7181 & 13.3633 & 242792 \\
\hline 6 & 0.985 & 3.95 & 1.648 & 2.49 & 0.9381 & 5.9357 & 28.0589 & 125632 \\
\hline 7 & 1.074 & 3.24 & 1.886 & 2.42 & 0.9784 & 6.8255 & 23.8623 & 96440 \\
\hline 8 & 0.975 & 6.59 & 1.797 & 4.59 & 0.9657 & 6.2512 & 27.5191 & 54712 \\
\hline 9 & 1.008 & 9.78 & 2.117 & 8.67 & 0.9447 & 8.0332 & 13.9375 & 48888 \\
\hline 10 & 0.988 & 2.88 & 2.474 & 2.64 & 0.9521 & 8.4807 & 10.6534 & 150920 \\
\hline 11 & 0.981 & 11.21 & 2.613 & 10.87 & 0.9165 & 9.0372 & 11.6882 & 51784 \\
\hline 12 & 0.963 & 0.55 & 2.784 & 0.53 & 0.9338 & 9.0238 & 1.8538 & 922080 \\
\hline
\end{tabular}

Because the $37 \mathrm{GHz}$ data provide more information for secondary forcing than the $10 \mathrm{GHz}$ data, the remainder of the data analysis in this study is illustrated with results for $W_{37}$ data. Note that all procedures and analyses described for $W_{37}$ data have also been carried out for the $W_{10}$ data and final results are reported (Sect. 3.3).

Figure 10 also shows that variations of $W^{1 / 2}$ caused by $U_{10}$ from 3 to $20 \mathrm{~m} \mathrm{~s}^{-1}$ are much larger than the regional and seasonal variations of $W^{1 / 2}$. While this is expected (because $U_{10}$ is a primary forcing factor), this also points out that we need to evaluate whether these regional and seasonal variations are statistically significant. For this, we grouped the values of $a$ and $b$ in two ways: (1) by month, with the full range of geographical variability (over all 12 regions) for each month; and (2) by region, with the full range of seasonal variability (over all 12 months) for each region. The ANOVA test applied to both groups showed that the seasonal variations are not statistically significant, while the regional variations are.
We illustrate this in Fig. 11 with values for $b$; similar graphs for $a$ show the same results. Figure 11a shows the seasonal cycle for the regionally averaged $b$ values with error bars $( \pm 1 \mathrm{SD})$ representing the regional variability. It is clear that the seasonal variations of the regionally averaged $b$ values lie within the regional variability. That is, variations of $b$ from month to month are statistically undistinguishable. Figure $11 \mathrm{~b}$ illustrates why variations of $b$ from region to region are significantly different. The graph shows the annually averaged $b$ values for each region with error bars representing the seasonal variability. It is clear that the geographical variations are not lost in the seasonal variability.

\subsubsection{Quantifying SST variations}

The regional differences in Fig. 11b are the variations that we want to quantify with coefficients $a$ and $b$ in terms of secondary factors. The deviations of the regional regression coefficients $a$ and $b$ from the regression coefficients $A=10.77 \times 10^{-5}$ and $B=1.789$ of the general $W\left(U_{10}\right)$ de- 

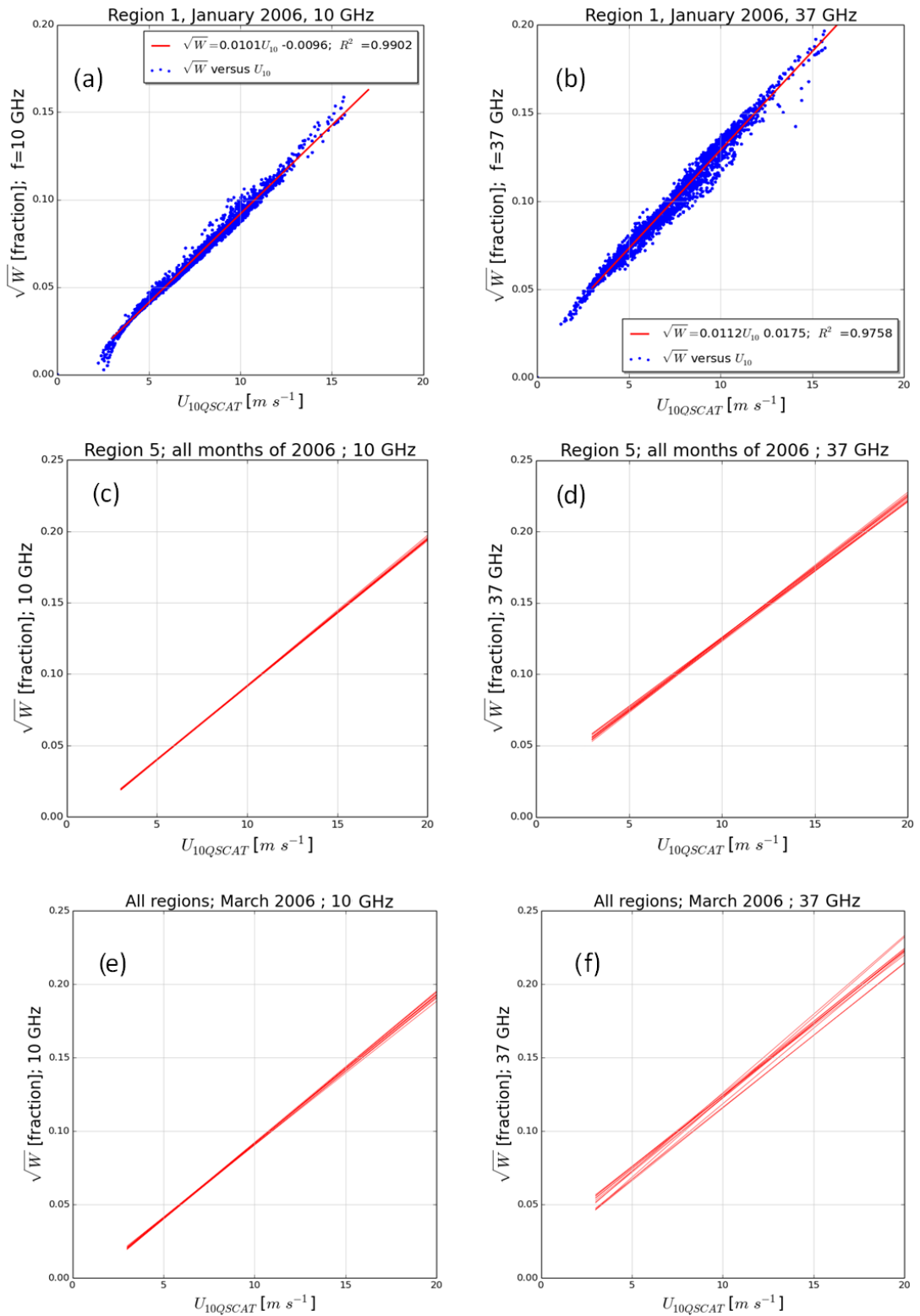

Figure 10. Linear fits of $W^{1 / 2}$ vs. $U_{10}$ for region 1 for January 2006 at $10 \mathrm{GHz}$ (a) and $37 \mathrm{GHz}$ (b); region 5 for all months of 2006 at $10 \mathrm{GHz}$ (c) and $37 \mathrm{GHz}$ (d); regions 1-12 for March 2006 at $10 \mathrm{GHz}$ (e) and $37 \mathrm{GHz}$ (f).

pendence (Eq. 11) give a sense for the magnitude of these variations. The PD between the annually averaged $\langle a\rangle$ and $A$ is about $5 \%$ (average for all regions); the average PD between $\langle b\rangle$ and $B$ is $50 \%$. These regional differences can be caused by any or all other secondary factors. It is not trivial to separate (deconvolve) the effects of different factors influencing $W$ data. Because our proxy analysis of the wave field effect produced limited results (Sect. 3.1.3), quantification of the regional differences in terms of wave field with the data we use is not practical. Meanwhile Fig. 3b shows that SST is a distinct characteristic for different regions. This suggests that quantifying the variations of coefficients $a$ and $b$ in terms of SST is a viable possibility. We thus proceed with deriving expressions $a(T)$ and $b(T)$ for the regional variations of the $W$ data; such results are useful to evaluate how well SST can account for the regional variations.

We derived $a(T)$ and $b(T)$ for $W$ data at $37 \mathrm{GHz}$ by relating annually averaged $a$ and $b$ values to the annually averaged $T$ for each region (Fig. 12). Figure 12c shows the monthly values of coefficients $b$ for each region and thus demonstrates how the data points in Fig. 12b have been formed; a similar procedure is used for the data points in Fig. 12a. As in Fig. 11b, the error bars $( \pm 1 \mathrm{SD})$ represent the seasonal variability of SST (horizontal bars) and coefficients 

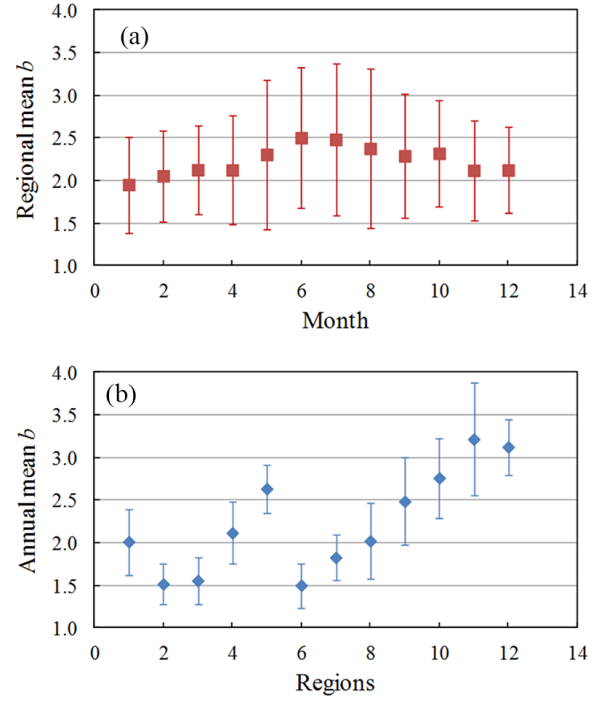

Figure 11. Regional and seasonal variations: (a) regionally averaged $b$ values for each month with error bars $( \pm 1$ standard deviation) representing the regional variability; (b) annually averaged $b$ values for each region with error bars representing the seasonal variability.

$a$ and $b$ (vertical bars). A second order polynomial is fitted to the data points in Fig. 12a; a linear fit is applied to the data in Fig. 12b. The coefficients of determination for the derived SST dependences are $R^{2}=0.57$ for $a(T)$ and $R^{2}=0.87$ for $b(T)$. Such $R^{2}$ values are consistent with the expectation that SST, being a static secondary factor, affects $W$ more via the intercept $b$ than via the slope $a$.

To evaluate the performance of the quadratic vs. cubic wind speed dependence in Eq. (6), we also derived SSTdependent coefficients $a(T)$ and $b(T)$ for $n=3$ following the same procedure as for the case of $n=2$. We applied Eq. (5b) with $n=3$ to $W_{37}$ data for all months in regions $4,5,6$, and 12; we verified that differences due to the use of 4 instead of 12 regions are not significant. Coefficients $a$ and $b$ were calculated from the $m$ and $c$ values and graphs similar to those in Fig. 12 were produced. Linear fits for both $a$ and $b$ were applied to these graphs.

\subsection{New parameterization of whitecap fraction}

New parameterizations for the whitecap fraction $W\left(U_{10}, T\right)$ were obtained from 2006 satellite-based $W$ data by replacing the fixed coefficients in Eqs. (10)-(11) with SST-dependent coefficients:

$W=a(T)\left[U_{10}+b(T)\right]^{2}$,

where

$a(T)=a_{0}+a_{1} T+a_{2} T^{2}$,

$b(T)=b_{0}+b_{1} T$
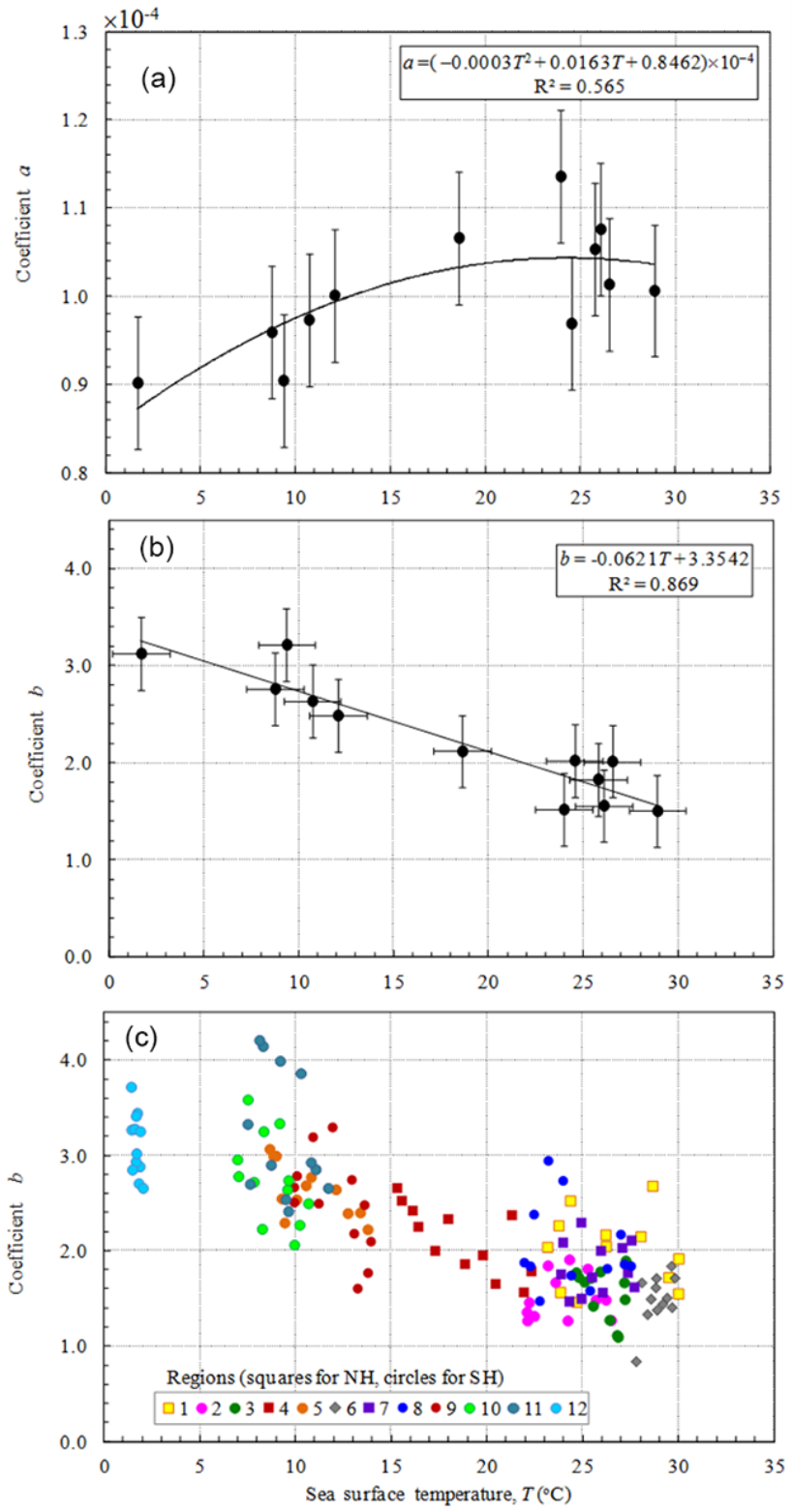

Figure 12. Sea surface temperature dependences of (a) coefficient $a$ (slope) and (b) coefficient $b$ (intercept) in the $W\left(U_{10}\right)$ dependence. Each point is the annual mean for a different region. The error bars indicate \pm 1 standard deviation for SST (horizontal bars) and coefficients (vertical bars). Panel (c) shows the monthly values of coefficients $b$ for each region that form one data point in (b). Regions in Northern Hemisphere (NH) are shown with squares; regions in Southern Hemisphere (SH) are shown with circles. The diamonds are for region 6 at the Equator.

and the coefficients for data at 10 and $37 \mathrm{GHz}$ are given in Table 5 together with their $95 \%$ CIs from the fitting procedure. To evaluate the derived $W\left(U_{10}, T\right)$ parameterizations, the whitecap fraction is calculated with Eqs. (13)-(14) and compared to both parameterized $W$ values and to satellitebased $W$ data. 
Table 5. Coefficients for the SST dependence of the parametric coefficients $a$ and $b$ in Eq. (14) with their $95 \%$ CIs from the fitting procedure. The temperature-dependent parametric coefficients $a(T)$ and $b(T)$ are used in parameterization $W\left(U_{10}, T\right)$ (Eq. 13) derived from satellitebased $W$ data for 10 and $37 \mathrm{GHz}$ for 2006.

\begin{tabular}{lrrrrr}
\hline Data set & $a_{0} \pm 95 \% \mathrm{CI}$ & $a_{1} \pm 95 \% \mathrm{CI}$ & $a_{2} \pm 95 \% \mathrm{CI}$ & $b_{0} \pm 95 \% \mathrm{CI}$ & $b_{1} \pm 95 \% \mathrm{CI}$ \\
\hline$W_{10}$ & $1.08 \times 10^{-4}$ & $-2.45 \times 10^{-7}$ & $-1.45 \times 10^{-9}$ & -1.203 & $9.9612 \times 10^{-3}$ \\
& $\pm 1.33 \times 10^{-6}$ & $\pm 1.91 \times 10^{-7}$ & $\pm 5.78 \times 10^{-9}$ & $\pm 1.91 \times 10^{-2}$ & $\pm 9.53 \times 10^{-4}$ \\
\hline$W_{37}$ & $8.46 \times 10^{-5}$ & $1.63 \times 10^{-6}$ & $-3.35 \times 10^{-8}$ & 3.354 & $-6.2 \times 10^{-2}$ \\
& $\pm 3.75 \times 10^{-6}$ & $\pm 5.46 \times 10^{-7}$ & $\pm 1.65 \times 10^{-8}$ & $\pm 9.72 \times 10^{-2}$ & $\pm 4.85 \times 10^{-3}$ \\
\hline
\end{tabular}

\subsubsection{Comparisons to $W$ parameterizations}

The $W\left(U_{10}, T\right)$ parameterization for $37 \mathrm{GHz}$ is used here. The $W$ values from SAL13 $(37 \mathrm{GHz})$ and MOM80 are used as references for PD calculations and significance tests (Sect. 2.3.3). All parameterizations are run for wind speeds from 3 to $20 \mathrm{~m} \mathrm{~s}^{-1}$.

Figure 13a compares $W$ values from the derived $W\left(U_{10}, T\right)$ parameterization at three fixed SST values $(T=$ 2, 12 , and $28^{\circ} \mathrm{C}$ ). Large changes of SST (from 2 to $28^{\circ} \mathrm{C}$ ) bring relatively small variations between the wind speed trends of $W$ at different $T$ values. The PDs between the three curves are no more than $15 \%$; indeed, significance tests show that the $W$ values at any $T$ remain statistically the same. In addition, $W$ values at any $T$ are not significantly different from the $W$ predictions of the global quadratic $W\left(U_{10}\right)$ parameterization.

These results qualitatively illustrate the relative contributions of the implicit and explicit accounts for SST effect in the derived parameterization. Namely, large part of the SST and other influences on $W$ is taken care of implicitly by using the quadratic wind speed exponent. Much smaller variations are explicitly expressed with the temperature-dependent coefficients. Taken together, the set of parametric coefficients $-n=2, a(T)$, and $b(T)-$ accounts for the (i) full SST effect (i.e., influence on both the trend and the spread of the $W$ data); and (ii) globally averaged effects of all other secondary factors (i.e., influences only on the trend of $W$ data).

We verify the validity of this deduction by comparing in Fig. 13b $W$ values obtained with the quadratic and cubic $W\left(U_{10}, T\right)$ parameterizations at $T=20^{\circ} \mathrm{C}$; MOM80 and SAL13 at $37 \mathrm{GHz}$ are shown for reference. The $W$ values from the cubic $W\left(U_{10}, T\right)$ parameterization are not statistically different from those obtained with either the quadratic $W\left(U_{10}, T\right)$ or SAL13 for low winds $\left(<10 \mathrm{~m} \mathrm{~s}^{-1}\right)$. Different trends of the $W$ values at higher wind speeds suggest that accounting explicitly for SST via $a(T)$ and $b(T)$ in the physically expected cubic wind speed dependence is not sufficient to replicate the satellite-based $W$ data. In other words, when the wind speed exponent $n$ is not adjusted to the data but instead follows the physically determined cubic dependence, explicit representation of the SST effect alone via the parametric coefficients $a(T)$ and $b(T)$ cannot account for all
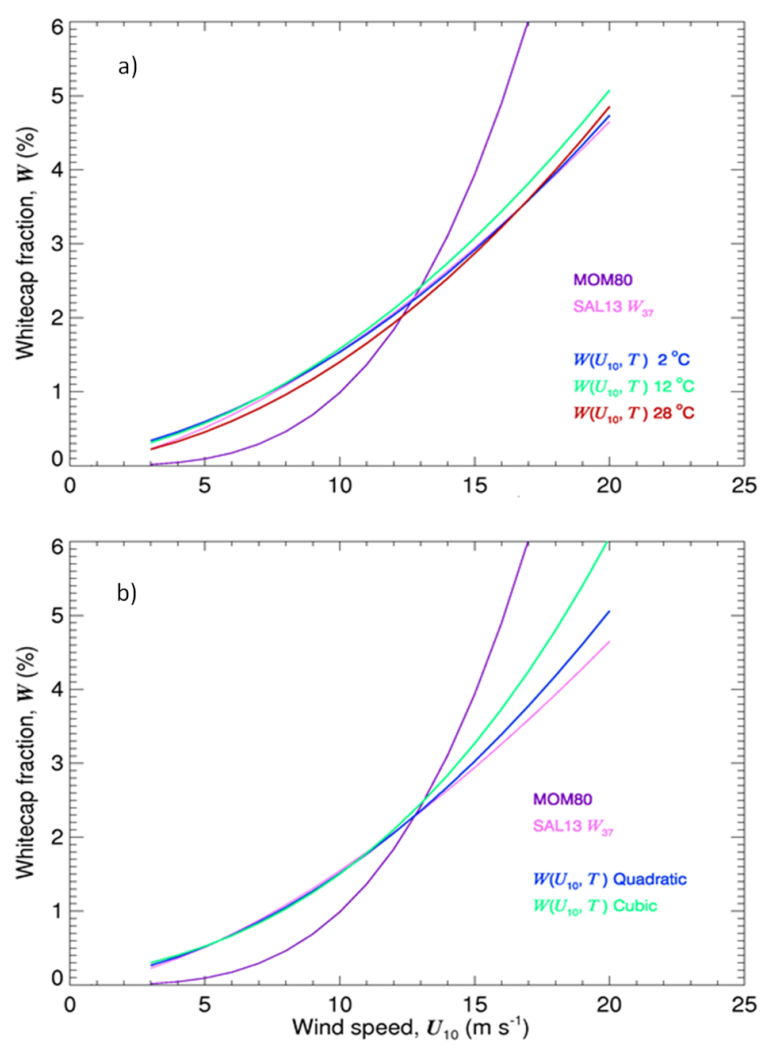

Figure 13. (a) Comparison of the new parameterization $W\left(U_{10}, T\right)$ (Eqs. 13-14) at three fixed SST values $\left(T=28^{\circ} \mathrm{C}\right.$, red line; $T=$ $12^{\circ} \mathrm{C}$, green line; $T=2{ }^{\circ} \mathrm{C}$, blue line) to the parameterizations of Salisbury et al. (2013, SAL13) (Eq. 1) for $37 \mathrm{GHz}$ (magenta line) and Monahan and O'Muircheartaigh (1980, MOM80) (Eq. 3) (purple line). (b) Comparison of the new $W\left(U_{10}, T\right)$ parameterizations with quadratic (Eqs. 13-14, blue line) and cubic (green line) wind speed exponents at $T=20^{\circ} \mathrm{C}$ to the parameterizations of SAL13 for $37 \mathrm{GHz}$ (magenta line) and MOM80 (purple line).

observed variations of $W$. The implication is that when using the cubic wind speed exponent, more secondary factors should be introduced explicitly.

The PD between the trends of the derived $W\left(U_{10}, T\right)$ and MOM80 $W\left(U_{10}\right)$ is from 5 to $175 \%$ with the largest PDs for wind speeds below $7 \mathrm{~m} \mathrm{~s}^{-1}$. Figure 13 illustrates this with the different trends of the two parameterizations. 


\subsubsection{Comparisons to $W$ data}

Here, we evaluate how well the derived whitecap fraction parameterizations model the trend and spread of the satellitebased $W$ data. The parameterized $W$ values are calculated using $U_{10}$ and $T$ from the whitecap database (Sect. 2.2.1).

Figure 14a compares $W$ values predicted with both new parameterizations, $W\left(U_{10}\right)$ and $W\left(U_{10}, T\right)$, to the same in situ data plotted in Fig. $1 \mathrm{~b}$ and to independent satellite-based $W$ data for 10 and $37 \mathrm{GHz}$ from 17 March 2007. Comparisons to the in situ $W$ data demonstrate order-of-magnitude consistency of the $W$ values from the new parameterizations. The new global $W\left(U_{10}\right)$ parameterizations (black symbols in Fig. 14a) follow reasonably well the wind speed trends of the satellite-based $W$ data. The $W$ values predicted with the new $W\left(U_{10}, T\right)$ parameterization (red and cyan symbols in Fig. 14a) are spread as the satellite-based $W$ data. The cluster of $W$ values predicted with $W\left(U_{10}, T\right)$ are statistically different from the MOM80 $W\left(U_{10}\right)$ parameterization. This is the most important result of this study: we demonstrate that by accounting for at least one secondary factor, we are able to model both the trend and the spread of the $W$ values.

Note in Fig. 14a that the new $W\left(U_{10}, T\right)$ parameterization does not predict the spread of the satellite-based $W$ data entirely. This suggests that accounting explicitly for SST in a $W$ parameterization is not enough to replicate all natural variability (spread) of $W$. This is consistent with our general understanding of the need to explicitly include many secondary factors in $W$ parameterizations, not just SST (Sect. 2.1).

Though SST entails small variations in the trend of $W$ with $U_{10}$ (Figs. 13a and 14a), an important consequence of the newly derived $W\left(U_{10}, T\right)$ parameterization is that it shapes significantly different spatial distribution compared to cubic and higher wind speed dependences like that of the MOM80. Figure $14 \mathrm{~b}$ shows a difference map between the global annual average $W$ distributions for 2006. MOM80 relationship yields a wider $W$ range with higher values in regions with the highest wind speeds. In particular, this occurs between about 40 and $70^{\circ}$ in the Southern Ocean and in the North Atlantic. The latitudinal variations from the Equator to the poles are more pronounced when using the MOM80 relationship as compared to Eqs. (13)-(14). The new $W\left(U_{10}, T\right)$ parameterization provides a global spatial distribution with similar patterns, but the absolute values are lower at high latitudes and higher at low latitudes. Note that in most studies, as in this study, $W\left(U_{10}\right)$ of MOM80 is extrapolated beyond the range of the data from which it was derived (Sect. 1). This could contribute to the large differences between the two parameterizations at higher wind speeds (and especially in cold waters).
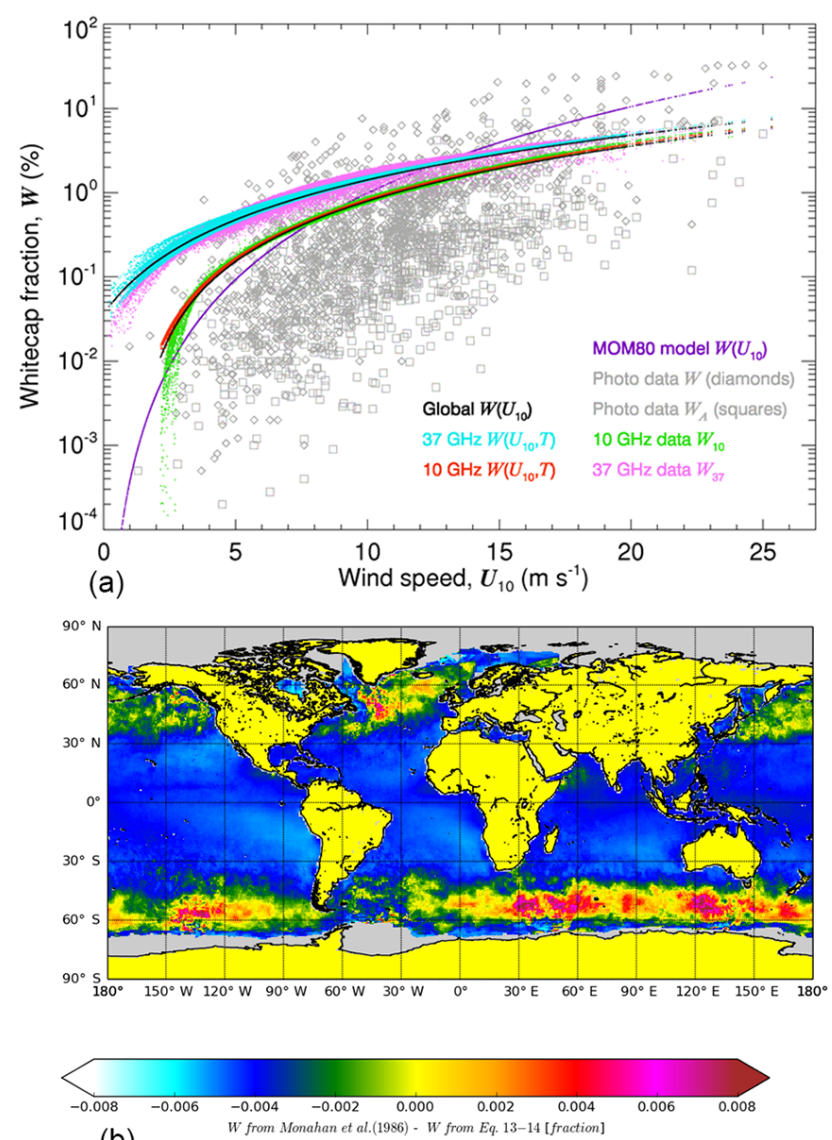

(b)

Figure 14. (a) In situ $W$ data as in Fig. 1b (gray symbols) and satellite-based $W$ data for 17 March 2007 at 10 and $37 \mathrm{GHz}$ (green and magenta symbols, respectively) compared to $W$ values obtained from $W\left(U_{10}\right)$ for 10 and $37 \mathrm{GHz}$ (black symbols, Eqs. 10-11) and $W\left(U_{10}, T\right)$ for 10 (red) and $37 \mathrm{GHz}$ (cyan, Eqs. 13-14). (b) Difference map of annual average $W$ distribution for 2006 calculated from the Monahan and O'Muircheartaigh (1980, MOM80) $W\left(U_{10}\right)$ parameterization (Eq. 3) minus $W\left(U_{10}, T\right)$ from Eqs. (13)-(14). The calculations use wind speed $U_{10}$ and SST $T$ from the whitecap database.

\subsection{Sea spray aerosol production}

The newly derived $W\left(U_{10}, T\right)$ parameterization (Eqs. 1314) was used to estimate the global annual average emission of super-micron SSAs using M86 SSSF (Eq. 4'). The total (i.e., size-integrated) annual SSA mass emission for 2006 is $4359.69 \mathrm{Tg}_{\text {year }}{ }^{-1}\left(4.4 \times 10^{12} \mathrm{~kg} \mathrm{year}^{-1}\right)$. This is about $50 \%$ larger than that calculated with the M86 SSSF using MOM80 (Eq. 4), 2915 Tg year $^{-1}\left(2.9 \times 10^{12} \mathrm{~kg} \mathrm{year}^{-1}\right)$. Because we have shown that the new $W\left(U_{10}, T\right)$ and MOM80 $W\left(U_{10}\right)$ are significantly different (Sect. 3.3.2), we infer that the SSA emissions based on SSSFs using each parameterization in combination with the same shape factor (Eq. $4^{\prime}$ ) also differ significantly. The two estimates of SSA emissions are calculated using the same modeling tool (Sect. 2.4) and 
the same input data (Sect. 2.2.1). With our new parameterization of the magnitude factor, the $50 \%$ difference includes explicit account for the SST effect on $W$. The spatial distribution of the mass emission rates obtained with SSSFs using the new $W\left(U_{10}, T\right)$ is shown in Fig. 15a. The SSA emissions obtained with the new and the MOM80 $W\left(U_{10}\right)$ parameterizations mimic the patterns of the $W$ distributions. The differences are mapped in Fig. 15b.

Previously modeled total dry SSA mass emissions vary by 2 orders of magnitude because of a variety of uncertainty sources (Sect. 1): $(2.2-22) \times 10^{12} \mathrm{~kg} \mathrm{year}^{-1}$ (Textor et al., 2006, their Fig. 1a; de Leeuw et al., 2011, their Table 1); and (2-74) $\times 10^{12} \mathrm{~kg} \mathrm{year}^{-1}$ for long-term averages (over 25 years) (G14, their Table 2, excluding three outliers). The impact of the modeling method used has to be acknowledged, too. Grythe et al. (2014) suggest that the spread in published estimates of global emission based on the same M86 SSSF (Eq. 4), from $3.3 \times 10^{12}$ to $11.7 \times 10^{12} \mathrm{~kg} \mathrm{year}^{-1}$ (Lewis and Schwartz, 2004) can be attributed to differences in model input data and resolution differences. An example of the same SSSF yielding different results when applied in different models is also seen in the work of de Leeuw et al. (2011, their Table 1).

For a meaningful comparison of our results to SSA emissions obtained with other SSSFs, we attempt to remove (or at least minimize) the impact of the modeling method. G14 used the same model (i.e., input data and configuration) to evaluate 21 SSSFs, including that of M86, against measurements. We thus can infer a "modeling" factor using our and G14 results obtained with M86 SSSF. We find that the G14 estimate of SSA emission from M86 $\left(5.20 \times 10^{12} \mathrm{~kg} \mathrm{year}^{-1}\right)$ is 1.78 times larger than our estimate of $2.9 \times 10^{12} \mathrm{~kg} \mathrm{year}^{-1}$ from M86 and MOM80. We apply this factor of 1.78 to our SSA emission estimated with the new $W\left(U_{10}, T\right)$ parameterization and obtain a "model-scaled" value of $7.78 \times 10^{12} \mathrm{~kg} \mathrm{year}^{-1}$. Our modelscaled estimate of the SSA emission is close to the median $5.91 \times 10^{12} \mathrm{~kg}_{\text {year }}{ }^{-1}$ of the SSA emissions reported by G14. This shows that an SSSF with a magnitude factor derived from satellite-based $W$ data provides reasonable and realistic predictions of the SSA emission.

To narrow down this broad assessment, we now look at the SSSFs evaluated by G14 which account for the SST effect on SSA emissions. There are four such SSSFs in the G14 study (see their Table 2): S11T of Sofiev et al. (2011), G03T of Gong (2003), J11T of Jaeglé et al. (2011), and G13T of G14. To minimize differences caused by using different size ranges, we focus on S11T and G13T, both applied to dry SSA diameters $D_{\mathrm{p}}=r_{80}$ (Sect. 2.4) from 0.01 to $10 \mu \mathrm{m}$. The upper limit is the same as in our study, while the lower limit is extended to submicron sizes, which, as we have seen (Sect. 2.4.2), introduces a discrepancy of at most $14 \%$.

The original Sofiev et al. (2011) SSSF is based on the M86 SSSF (Eq. 4) combined with data from laboratory experiments by Mårtensson et al. (2003) to account for SST and
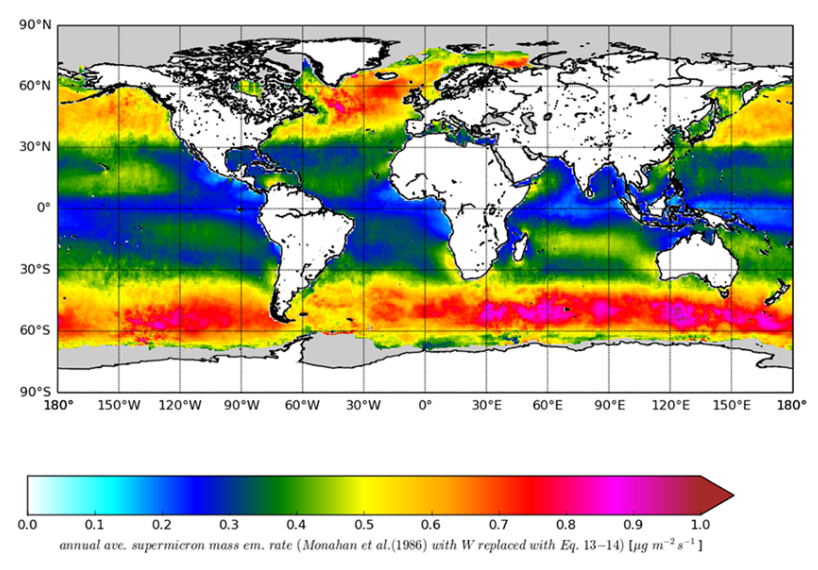

a
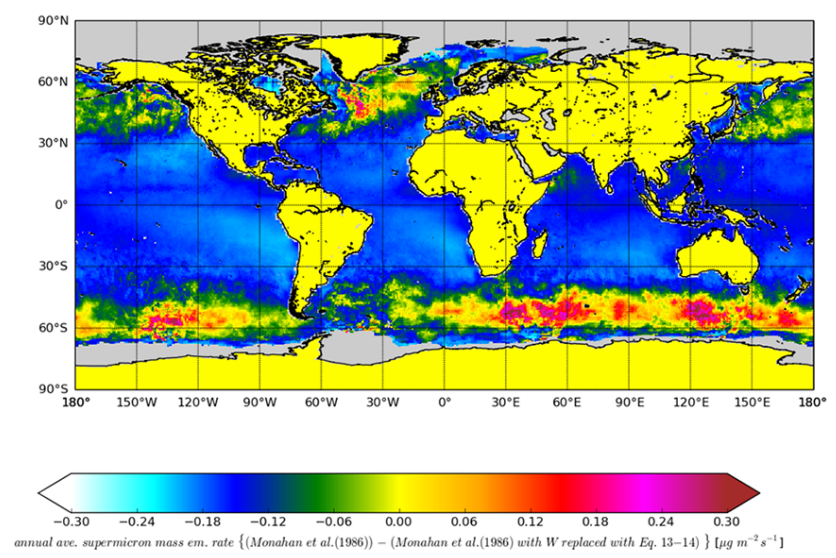

b

Figure 15. (a) Annual average super-micron mass emission rate for 2006 in $\mu \mathrm{g} \mathrm{m}^{-2} \mathrm{~s}^{-1}$ calculated from Eq. $4^{\prime}$. (b) Difference map between the annual average super-micron SSA mass emission rate calculated from the Monahan et al. (1986) SSSF and the annual average super-micron SSA mass emission rate calculated from the Monahan et al. (1986) SSSF where $W$ is replaced with Eqs. (13)(14). The calculations use wind speed $U_{10}$ from QuikSCAT in the whitecap database.

salinity effects and a field experiment by Clarke et al. (2006) to extend the size range. In the G14 study, the salinity weight proposed by Sofiev et al. (2011) is not applied. At a reference salinity of $33 \%$, S11T estimates an SSA emission of $2.59 \times 10^{12} \mathrm{~kg} \mathrm{year}^{-1}$. Without the SST effect (the SST factor set to unity), the SSA emission estimated with S11 is $5.87 \times 10^{12} \mathrm{~kg}$ year $^{-1}$. With everything else the same except for the SST factor in source functions S11 and S11T, we evaluate that accounting for the SST effect results in changes by $56 \%$. Correcting for $14 \%$ discrepancy due to extended lower size limit, we infer a $42 \%$ change when the SST effect is included in the SSSF. This is comparable to the $50 \%$ change involving SST effect in our case. We surmise that parameterizing additional influences on $W$ is a viable way to account and explain some of the uncertainty of SSA emissions. 
Grythe et al. (2014) used a large data set of ship observations to develop G13T by changing both the magnitude and the shape factors. The authors modified the SSSF of Smith and Harrison (1998) (a sum of two log-normal distributions) to add an extra log-normal mode to cover the accumulation mode. They also added the empirically based SST factor (a third order polynomial) proposed by Jaeglé et al. (2011). With G13T, G14 estimate an SSA emission of $8.91 \times 10^{12} \mathrm{~kg} \mathrm{year}^{-1}$. The functional forms of the magnitude (involving the SST effect) and shape (modeling the size distribution) factors of G13T and S11T are very different. This makes it difficult to evaluate the relative contribution of the magnitude and shape factors for variations in SSA emissions. Our results can help.

The shape factors of S11T and our SSSF using $W\left(U_{10}, T\right)$ have a similar (not identical) functional form (that of M86, original and modified), but the functional forms accounting for SST are different. Our SSA emission estimate is about $67 \%$ higher than that of S11T. Allowing for $14 \%$ discrepancy due to the lower size limit, we find that different approaches to account for SST can lead to about $71 \%$ variation in SSA emissions. Compared to G13T, our SSSF using $W\left(U_{10}, T\right)$ has a different shape factor (that of M86 vs. lognormal), and a similar (but not identical) functional form for the SST effect (polynomial). Our SSA emission estimate is about $15 \%$ lower than that of G13T. Allowing for $14 \%$ size discrepancy, we find that different shape factors can lead to about $2 \%$ variation in SSA emissions.

On the basis of these assessments, we can state that the inclusion of the SST effect in the magnitude factor and/or the choice of the shape factor (size range and model for the size distribution) in the SSSF can explain up to $71 \%$ of the variations in the predictions of SSA emissions. The spread in SSA emission can thus be constrained by more than $75 \%$ when improvements of both the magnitude and the shape factor are pursued. Our results on the $W$ parameterization (Fig. 14a) suggest that accounting for more secondary forcing in the magnitude factor would explain more fully the spread among SSA emissions.

\section{Conclusions}

The objective of the study presented here is to evaluate how accounting for natural variability of whitecaps in the parameterization of the whitecap fraction $W$ would affect mass flux predictions when using a sea spray source function based on the discrete whitecap method. The study uses satellite-based $W$ data estimated from measurements of the ocean surface brightness temperature $T_{\mathrm{B}}$ by satellite-borne microwave radiometers at frequencies of 10 and $37 \mathrm{GHz}, W_{10}$ and $W_{37}$. Global and regional data sets comprising $W_{10}$ and $W_{37}$ data, wind speed $U_{10}$, and sea surface temperature $T$ for 2006 were used to derive parameterizations $W\left(U_{10}\right)$ and $W\left(U_{10}, T\right)$. The SSSF of Monahan et al. (1986) combined with the new
$W\left(U_{10}, T\right)$ was used to estimate sea spray aerosol emission. The conclusions of the study are the following.

The global $W$ data set can be parameterized reasonably well with a quadratic correlation between $W$ and $U_{10}$ (Eqs. 10-11 and Sect. 3.1.1). The unconventional positive $y$ intercept for $W_{37}\left(U_{10}\right)$ could be interpreted as a mathematical expression of the static forcing that given seawater properties (e.g., effects of SST, salinity, and surfactant concentrations) impart on whitecaps. Parameterization $W\left(U_{10}\right)$ derived with an independent data set ( $U_{10}$ from ECMWF instead of QuikSCAT) helps to determine that the intrinsic correlation between $W$ and $U_{10}$ is most likely less than about $10 \%$ (Sect. 3.1.2). Proxy analysis of satellite-based $W$ data at increasing and decreasing wind speeds (Table 3) yields limited results for the effect of the wave field on $W$ (Sect. 3.1.3). The derived $W\left(U_{10}\right)$ for both $W_{10}$ and $W_{37}$ replicate the trend of the satellite-based data well (Fig. 14a). That is, the adjusted quadratic wind speed exponent in $W\left(U_{10}\right)$ accounts implicitly for most of the SST variations. The new quadratic $W\left(U_{10}\right)$ predicts a whitecap fraction significantly different from that obtained with the widely used $W\left(U_{10}\right)$ of MOM80.

Applying the global $W\left(U_{10}\right)$ parameterization on regional scale shows that the seasonal variations of its regression coefficients $a$ and $b$ are not statistically significant, while the regional variations are. On this basis, by relating annually averaged $a$ and $b$ values to the annually averaged $T$ for each region (Fig. 12), the explicit SST dependences $a(T)$ and $b(T)$ for data at 10 and $37 \mathrm{GHz}$ were derived (Sect. 3.3 and Table 5). The new $W\left(U_{10}, T\right)$ parameterization (Eqs. 13-14) is able to model the variability (spread) of the satellite-based $W$ data (Fig. 14a). The capability of the new $W\left(U_{10}, T\right)$ parameterization to model both the trend and the spread of the $W$ data sets it apart from all other $W\left(U_{10}\right)$ parameterizations (e.g., MOM80 and SAL13). Results show that besides SST, one needs to include explicitly other secondary factors in order to model the full spread of the satellitebased $W$. Including the SST effect via $a(T)$ and $b(T)$ in the physically expected cubic wind speed dependence is not sufficient to replicate the trend of the satellite-based $W$ values. While SAL13 analysis of the satellite-based whitecap database demonstrated the influences of secondary factors on whitecap fraction, our study goes a step further in using the satellite-based $W$ data to parameterize one of these influences (that of SST).

Application of the new $W\left(U_{10}, T\right)$ parameterization in the Monahan et al. (1986) SSSF resulted in a total (integrated only over super-micron sizes) SSA mass emission estimate of $4359.69 \mathrm{Tg}_{\text {year }}^{-1}\left(4.4 \times 10^{12} \mathrm{~kg} \mathrm{year}^{-1}\right)$ for 2006 . Scaled for modeling differences (Sect. 3.4), this estimate is $7.78 \times 10^{12} \mathrm{~kg}$ year $^{-1}$, which is comparable to previously reported estimates. Comparing our and previous total SSA emissions, we have been able to assess to what degree accounting for the SST influence on whitecaps can explain the spread of SSA emissions. SSA emissions obtained with the new $W\left(U_{10}, T\right)$ parameterization vary by $\sim 50 \%$. Different 
approaches to account for SST effect yield $\sim 71 \%$ variations. Different models for the size distribution applied to different size ranges can yield up to $42 \%$ variations in SSA emissions. Understanding and constraining the various sources of uncertainty in the SSSF would eventually improve the accuracy of SSSF predictions. Including the natural variability of whitecaps in the SSSF magnitude factor is a viable way toward such accuracy improvement.

While the new $W\left(U_{10}, T\right)$ parameterization is able to model the trend and the spread of the satellite-based $W$ data, the SST variations are relatively small. To model the full variability of $W$, future work should focus on the parameterization of the wave field effect. The extended version of the whitecap database contains wave field characteristics and is thus suitable for such quantification. It is recommended that the extended whitecap database includes wind speed data from independent source(s) matched in time and space at WindSat resolution.

\section{Data availability}

The data analysis and the results reported in this study are available from the corresponding author M. D. Anguelova (maggie.anguelova@nrl.navy.mil).

Acknowledgements. This study is partly funded by SRON (Netherlands Institute for Space Research), through the Dutch users support programme GO-2. MDA was sponsored by the Office of Naval Research, NRL program element 61153N, WU 4500. GdL by was supported by the European Space Agency (Support to Science Element: Oceanflux Sea Spray Aerosol, contract no. 4000104514/11/I-AM), the Centre of Excellence in Atmospheric Science funded by the Finnish Academy of Sciences Excellence (project no. 272041), the CRAICC project (part of the top-level research initiative).

Edited by: M. Schulz

Reviewed by: three anonymous referees

\section{References}

Albert, M. F. M. A., Schaap, M., de Leeuw, G., and Builtjes, P. J. H.: Progress in the determination of the sea spray source function using satellite data, Journal of Integrative Environmental Sciences, 7, 159-166, 2010.

Albert, M. F. M. A., Schaap, M., Manders, A. M. M., Scannell, C., O'Dowd, C. D., and de Leeuw, G.: Uncertainties in the determination of global sub-micron marine organic matter emissions, Atmos. Environ., 57, 289-300, 2012.

Andreae, M. O. and Crutzen, P. J.: Atmospheric aerosols: biogeochemical sources and role in atmospheric chemistry, Science, 276, 1052-1058, 1997.

Andreas, E. L: Sea Spray and the turbulent air-sea heat fluxes, J. Geophys. Res., 97, 11429-11441, 1992.
Anguelova, M. D.: Assessing the utility of satellite-based whitecap fraction to estimate sea spray production and $\mathrm{CO}_{2}$ transfer velocity, IOP Conf. Ser.: Earth Environ. Sci., 35, 012002 , doi:10.1088/1755-1315/35/1/012002, 2016.

Anguelova, M. D. and Gaiser, P. W.: Skin depth at microwave frequencies of sea foam layers with vertical profile of void fraction, J. Geophys. Res., 116, C11002, doi:10.1029/2011JC007372, 2011.

Anguelova, M. D. and Gaiser, P. W.: Microwave emissivity of sea foam layers with vertically inhomogeneous dielectric properties, Remote Sens. Environ., 139, 81-96, 2013.

Anguelova, M. D. and Webster, F.: Whitecap coverage from satellite measurements: A first step toward modeling the variability of oceanic whitecaps, J. Geophys. Res., 111, C03017, doi:10.1029/2005JC003158, 2006.

Anguelova, M. D., Bettenhausen, M. H., and Gaiser, P. W.: Passive remote sensing of sea foam using physically-based models, in: Proceedings of the IGARSS 2006: IEEE International Geoscience and Remote Sensing Symposium, Denver, Colorado, USA, 31 July-4 August, 3659-3662, 2006.

Anguelova, M. D., Bobak, J. P., Asher, W. E., Dowgiallo, D. J., Moat, B. I., Pascal, R. W., and Yelland, M. J.: Validation of satellite-based estimates of whitecap coverage: approaches and initial results, in: Proceedings of the 16th Air-Sea Interaction conference, AMS, Phoenix, Arizona, USA, available at: http:// ams.confex.com/ams/pdfpapers/143665.pdf (last access: 17 October 2016), 2009.

Anguelova, M. D., Bettenhausen, M. H., Johnston, W. F., and Gaiser, P. W.: First extensive whitecap database and its use to study whitecap fraction variability, in: Proceedings of the 17th Air-Sea Interaction Conference, AMS, Annapolis, Maryland, USA, available at: http://ams.confex.com/ams/pdfpapers/ 174036.pdf (last access: 17 October 2016), 2010.

Asher, W. E. and Wanninkhof, R.: The effect of bubble-mediated gas transfer on purposeful dual-gaseous tracer experiments, J. Geophys. Res., 103, 10555-10560, 1998.

Barrie, L. A., Bottenheim, J. W., Schnell, R. C., Crutzen, P. J., and Rasmussen, R. A.: Ozone destruction and photochemical reactions at polar sunrise in the lower Arctic atmosphere, Nature, 334, 138-141, 1988.

Bettenhausen, M. H., Smith, C. K., Bevilacqua, R. M., Wang, N.-Y., Gaiser, P. W., and Cox, S.: A nonlinear optimization algorithm for WindSat wind vector retrievals, IEEE T. Geosci. Remote, 44, 597-610, 2006.

Blanchard, D. C.: The electrification of the atmosphere by particles from bubbles in the sea, Prog. Oceanogr., 1, 73-112, 1963.

Blanchard, D. C.: The production, distribution, and bacterial enrichment of the sea-salt aerosol, in: Air-sea exchange of gases and particles, edited by: Liss, P. S. and Slinn, W. G. N., D. Reidel Publishing Company, Dordrecht, the Netherlands, 407-454, 1983.

Bondur, V. and Sharkov, E.: Statistical properties of whitecaps on a rough sea, Oceanology, 22, 274-279, 1982.

Callaghan, A. H.: An improved whitecap timescale for sea spray aerosol production flux modeling using the discrete whitecap method, J. Geophys. Res.-Atmos., 118, 9997-10010, 2013.

Callaghan, A. H. and White, M.: Automated processing of sea surface images for the determination of whitecap coverage, J. Atmos. Ocean. Tech., 26, 383-394, 2009. 
Callaghan, A. H., de Leeuw, G., Cohen, L., and O'Dowd, C. D.: Relationship of oceanic whitecap coverage to wind speed and wind history, Geophys. Res. Lett., 35, L23609, doi:10.1029/2008GL036165, 2008.

Callaghan, A. H., Deane, G. B., and Stokes, M. D.: Two Regimes of Laboratory Whitecap Foam Decay: Bubble-Plume Controlled and Surfactant Stabilized, J. Phys. Oceanogr., 43, 1114-1126, 2013.

Chameides, W. L. and Stelson, A. W.: Aqueous-phase chemical processes in deliquescent sea-salt aerosols: a mechanism that couples the atmospheric cycles of S and sea salt, J. Geophys. Res.Atmos., 97, 20565-20580, 1992.

Chelton, D. B. and Freilich, M. H.: Scatterometer-based assessment of 10-m wind analyses from the operational ECMWF and NCEP numerical weather prediction models, Mon. Weather Rev., 133, 409-429, 2005.

Cicerone, R. J.: Halogens in the atmosphere, Rev. Geophys. Space Ge., 19, 123-139, 1981.

Clarke, A. D., Owens, S. R., and Zhou, J.: An ultrafine sea-salt flux from breaking waves: Implications for cloud condensation nuclei in the remote marine atmosphere, J. Geophys. Res., 111, D06202, doi:10.1029/2005JD006565, 2006.

de Leeuw, G., Andreas, E. L, Anguelova, M. D., Fairall, C. W., Lewis, E. R., O'Dowd, C. D., Schulz, M., and Schwartz, S. E.: Production flux of sea-spray aerosol, Rev. Geophys., 49, RG2001, doi:10.1029/2010RG000349, 2011.

Facchini, M. C., Rinaldi, M., Decesari, S., Carbone, C., Finessi, E., Mircea, M., Fuzzi, S., Ceburnis, D., Flanagan, R., Nilsson, E. D., de Leeuw, G., Martino, M., Woeltjen, J., and O'Dowd, C. D.: Primary submicron marine aerosol dominated by insoluble organic colloids and aggregates, Geophys. Res. Lett., 35, L17814, doi:10.1029/2008GL034210, 2008.

Fairall, C. W., Kepert, J. D., and Holland, G. J.: The effect of sea spray on surface energy transports over the ocean, The Global Atmosphere and Ocean System, 2, 121-142, 1994.

Falkowski, P. G., Barber, R. T., and Smetacek, V.: Biogeochemical controls and feedbacks on ocean primary production, Science, 281, 200-206, 1998.

Gaiser, P. W., St. Germain, K. M., Twarog, E. M., Poe, G. A., Purdy, W., Richardson, D., Grossman, W., Linwood Jones, W., Spencer D., Golba, G., Cleveland, J., Choy, L., Bevilacqua, R. M., and Chang, P. S.: The WindSat spaceborne polarimetric microwave radiometer: sensor description and early orbit performance, IEEE T. Geosci. Remote, 42, 2347-2361, 2004.

Garrett, W. D.: Stabilization of air bubbles at the air-sea interface by surface-active material, Deep-Sea Res., 14, 661-672, 1967.

Ghan, S. J., Guzman, G., and Hayder, A.-R.: Competition between sea salt and Sulfate particles as cloud condensation nuclei, J. Atmos. Sci., 55, 3340-3347, 1998.

Goddijn-Murphy, L., Woolf, D. K., and Callaghan, A. H.: Parameterizations and algorithms for oceanic whitecap coverage, J. Phys. Oceanogr., 41, 742-756, 2011.

Gong, S. L.: A parameterization of sea-salt aerosol source function for sub- and super-micron particles, Global Biogeochem. Cy., 17, 1097, doi:10.1029/2003GB002079, 2003.

Graedel, T. E. and Keene, W. C.: The budget and cycle of Earth's natural chlorine, Pure Appl. Chem., 68, 1689-1697, 1996.

Grythe, H., Ström, J., Krejci, R., Quinn, P., and Stohl, A.: A review of sea-spray aerosol source functions using a large global set of sea salt aerosol concentration measurements, Atmos. Chem. Phys., 14, 1277-1297, doi:10.5194/acp-14-1277-2014, 2014.

Hanson, J. L. and Phillips, O. M.: Wind sea growth and dissipation in the open ocean, J. Phys. Oceanogr., 29, 1633-1648, 1999.

Jaeglé, L., Quinn, P. K., Bates, T. S., Alexander, B., and Lin, J.-T.: Global distribution of sea salt aerosols: new constraints from in situ and remote sensing observations, Atmos. Chem. Phys., 11, 3137-3157, doi:10.5194/acp-11-3137-2011, 2011.

Kara, A. B., Wallcraft, A. J., and Bourassa, M. A.: Air-sea stability effects on the $10 \mathrm{~m}$ winds over the global ocean: Evaluations of air-sea flux algorithms, J. Geophys. Res.-Oceans, 113, C04009, doi:10.1029/2007JC004324, 2008.

Keene, W. C., Pszenny, A. A. P., Jacob, D. J., Duce, R. A., Galloway, J. N., Schultz-Tokos, J. J., Sievering, H., and Boatman, J. F.: The geochemical cycling of reactive chlorine through the marine troposphere, Global Biogeochem. Cy., 4, 407-430, 1990.

Keene, W. C., Khalil, M. A. K., Erickson, D. J., McCulloch, A., Graedel, T. E., Lobert, J. M., Aucott, M. L., Gong, S.-L., Harper, D. B., Kleiman, G., Midgley, P., Moore, R. M., Seuzaret, C., Sturges, W. T., Benkovitz, C. M., Koropalov, V., Barrie, L. A., and Li, Y.-F.: Composite global emissions of reactive chlorine from anthropogenic and natural sources: reactive chlorine emissions inventory, J. Geophys. Res., 104, 8429-8440, 1999.

Kleiss, J. M. and Melville, W. K.: The analysis of sea surface imagery for whitecap kinematics, J. Atmos. Ocean. Tech, 28, 219 243, 2011.

Koop, T., Kapilashrami, A., Molina, L. T., and Molina, M. J.: Phase transitions of sea-salt/water mixtures at low temperatures: implications for ozone chemistry in the polar marine boundary layer, J. Geophys. Res., 105, 26393-26402, 2000.

Lewis, E. R. and Schwartz, S. E.: Sea salt aerosol production: mechanisms, methods, measurements and models - A critical review, Geoph. Monog. Series, 152, American Geophysical Union, Washington D. C., 413 pp., 2004.

Luria, M. and Sievering, H.: Heterogeneous and homogeneous oxidation of $\mathrm{SO}_{2}$ in the remote marine atmosphere, Atmos. Environ. A-Gen., 25, 1489-1496, 1991.

Mårtensson, E. M., Nilsson, E. D., de Leeuw, G., Cohen, L. H., and Hansson, H.-C.: Laboratory simulations and parameterization of the primary marine aerosol production, J. Geophys. Res., 108, 4297, doi:10.1029/2002JD002263, 2003.

Medwin, H.: In situ acoustic measurements of microbubbles at sea, J. Geophys. Res., 82, 971-976, 1977.

Meissner, T. and Wentz, F. J.: The emissivity of the ocean surface between 6 and $90 \mathrm{GHz}$ over a large range of wind speeds and earth incidence angles, IEEE T. Geosci. Remote, 50, 3004-3026, 2012.

Melville, W. K.: The role of surface-wave breaking in air-sea interaction, Annu. Rev. Fluid Mech., 28, 279-321, 1996.

Monahan, E. C.: Oceanic Whitecaps, J. Phys. Oceanogr., 1, 139144, 1971.

Monahan, E. C. and Lu, M.: Acoustically relevant bubble assemblages and their dependence on meteorological parameters, IEEE J. Oceanic Eng., 15, 340-349, doi:10.1109/48.103530, 1990.

Monahan, E. C. and O'Muircheartaigh, I.: Optimal power-law description of oceanic whitecap coverage dependence on wind speed, J. Phys. Oceanogr., 10, 2094-2099, 1980. 
Monahan, E. C. and O'Muircheartaigh, I.: Whitecaps and the passive remote sensing of the ocean surface, Int. J. Remote Sens., 7, 627-642, 1986.

Monahan, E. C. and Woolf, D. K.: Comments on "Variations of whitecap coverage with wind stress and water temperature, J. Phys. Oceanogr., 19, 706-709, 1989.

Monahan, E. C., Fairall, C. W., Davidson, K. L., and Boyle, P. J.: Observed inter-relations between $10 \mathrm{~m}$ winds, ocean whitecaps and marine aerosols, Q. J. Roy. Meteor. Soc., 109, 379-392, 1983.

Monahan, E. C., Spiel, D. E., and Davidson, K. L.: A model of marine aerosol generation via whitecaps and wave disruption, in: Oceanic whitecaps: and their role in air-sea exchange processes, Monahan, E. C., Mac Niocaill, G., D. Reidel Publishing Company, Dordrecht, the Netherlands, 167-174, 1986.

Norris, S. J., Brooks, I. M., Moat, B. I., Yelland, M. J., de Leeuw, G., Pascal, R. W., and Brooks, B.: Near-surface measurements of sea spray aerosol production over whitecaps in the open ocean, Ocean Sci., 9, 133-145, doi:10.5194/os-9-133-2013, 2013 a.

Norris, S. J., Brooks, I. M., and Salisbury, D. J.: A wave roughness Reynolds number parameterization of the sea spray source flux, Geophys. Res. Lett., 40, 4415-4419, 2013 b.

O'Dowd, C. D. and de Leeuw, G.: Marine aerosol production: a review of the current knowledge, Philos. T. R. Soc. A, 365, 17531774, 2007.

O’Dowd, C. D., Lowe, J. A., Smith, M. H., and Kaye, A. D.: The relative importance of non-sea-salt sulphate and sea-salt aerosol to the marine cloud condensation nuclei population: An improved multi-component aerosol-cloud droplet parametrization, Q. J. Roy. Meteor. Soc., 125, 1295-1313, 1999.

O’Dowd, C. D., Facchini, M. C., Cavalli, F., Ceburnis, D., Mircea, M., Decesari, S., Fuzzi, S., Yoon, Y. J., and Putaud, J.-P.: Biogenically driven organic contribution to marine aerosol, Nature, 431, 676-680, 2004.

Ovadnevaite, J., Manders, A., de Leeuw, G., Ceburnis, D., Monahan, C., Partanen, A.-I., Korhonen, H., and O'Dowd, C. D.: A sea spray aerosol flux parameterization encapsulating wave state, Atmos. Chem. Phys., 14, 1837-1852, doi:10.5194/acp-14-18372014, 2014.

Paget, A. C., Bourassa, M. A., and Anguelova, M. D.: Comparing in situ and satellite-based parameterizations of oceanic whitecaps, J. Geophys. Res.-Oceans, 120, 2826-2843, 2015.

Pandey, P. C. and Kakar, R. K.: An empirical microwave emissivity model for a foam- covered sea, IEEE J. Ocean. Eng., 7, 135-140, 1982.

Partanen, A.-I., Dunne, E. M., Bergman, T., Laakso, A., Kokkola, H., Ovadnevaite, J., Sogacheva, L., Baisnée, D., Sciare, J., Manders, A., O'Dowd, C., de Leeuw, G., and Korhonen, H.: Global modelling of direct and indirect effects of sea spray aerosol using a source function encapsulating wave state, Atmos. Chem. Phys., 14, 11731-11752, doi:10.5194/acp-14-11731-2014, 2014.

Quilfen, Y., Prigent, C., Chapron, B., Mouche, A. A., and Houti, N.: The potential of QuikSCAT and WindSat observations for the estimation of sea surface wind vector under severe weather conditions, J. Geophys. Res., 112, C09023, doi:10.1029/2007JC004163, 2007.

Reising, S., Asher, W., Rose, L., and Aziz, M.: Passive polarimetric remote sensing of the ocean surface: The effects of surface roughness and whitecaps, paper presented at the Interna- tional Union of Radio Science, URSI Gen. Assem., Maastrict, the Netherlands, 2002.

Saiz-Lopez, A. and von Glasow, R.: Reactive halogen chemistry in the troposphere, Chem. Soc. Rev., 41, 6448-6472, 2012.

Salisbury, D. J., Anguelova, M. D., and Brooks, I. M.: On the variability of whitecap fraction using satellite-based observations, J. Geophys. Res.-Oceans, 118, 6201-6222, 2013.

Salisbury, D. J., Anguelova, M. D., and Brooks, I. M.: Global distribution and seasonal dependence of satellite-based whitecap fraction, Geophys. Res. Lett., 41, 1616-1623, 2014.

Savelyev, I. B., Anguelova, M. D., Frick, G. M., Dowgiallo, D. J., Hwang, P. A., Caffrey, P. F., and Bobak, J. P.: On direct passive microwave remote sensing of sea spray aerosol production, Atmos. Chem. Phys., 14, 11611-11631, doi:10.5194/acp14-11611-2014, 2014.

Sievering, H., Boatman, J., Gorman, E., Kim, Y., Anderson, L., Ennis, G., Luria, M., and Pandis, S.: Removal of sulphur from the marine boundary layer by ozone oxidation in sea-salt aerosols, Nature, 360, 571-573, 1992.

Sievering, H., Gorman, E., Ley, T., Pszenny, A., Springer-Young, M., Boatman, J., Kim, Y., Nagamoto, C., and Wellman, D.: Ozone oxidation of sulfur in sea-salt aerosol particles during the Azores Marine Aerosol and Gas Exchange experiment, J. Geophys. Res.-Atmos., 100, 23075-23081, 1995.

Smith, M. H. and Harrison, N. M.: The sea spray generation function, J. Aerosol Sci., 29, S189-S190, 1998.

Smith, M. H., Park, P. M., and Consterdine, I. E.: Marine aerosol concentrations and estimated fluxes over the sea, Q. J. Roy. Meteor. Soc., 119, 809-824, 1993.

Sofiev, M., Soares, J., Prank, M., de Leeuw, G., and Kukkonen, J.: A regional-to-global model of emission and transport of sea salt particles in the atmosphere, J. Geophys. Res., 116, D21302, doi:10.1029/2010JD014713, 2011.

Stramska, M. and Petelski, T.: Observations of oceanic whitecaps in the north polar waters of the Atlantic, J. Geophys. Res., 108, 3086, doi:10.1029/2002JC001321, 2003.

Tang, W., Yueh, S. H., Fore, A. G., and Hayashi, A.: Validation of Aquarius sea surface salinity with in situ measurements from Argo floats and moored buoys, J. Geophys. Res.-Oceans, 119, 6171-6189, doi:10.1002/2014JC010101, 2014.

Textor, C., Schulz, M., Guibert, S., Kinne, S., Balkanski, Y., Bauer, S., Berntsen, T., Berglen, T., Boucher, O., Chin, M., Dentener, F., Diehl, T., Easter, R., Feichter, H., Fillmore, D., Ghan, S., Ginoux, P., Gong, S., Grini, A., Hendricks, J., Horowitz, L., Huang, P., Isaksen, I., Iversen, I., Kloster, S., Koch, D., Kirkevåg, A., Kristjansson, J. E., Krol, M., Lauer, A., Lamarque, J. F., Liu, X., Montanaro, V., Myhre, G., Penner, J., Pitari, G., Reddy, S., Seland, Ø., Stier, P., Takemura, T., and Tie, X.: Analysis and quantification of the diversities of aerosol life cycles within AeroCom, Atmos. Chem. Phys., 6, 1777-1813, doi:10.5194/acp-6-1777-2006, 2006.

Thorpe, S. A.: On the clouds of bubbles formed by breaking windwaves in deep water, and their role in air-sea gas transfer, Philos. T. R. Soc. A., 304, 155-210, 1982.

Toba, Y. and Chaen, M.: Quantitative expression of the breaking of wind waves on the sea surface, Records of Oceanographic Works in Japan, 12, 1-11, 1973.

Wanninkhof, R., Asher, W. E., Ho, D. T., Sweeney, C., and McGillis, W. R.: Advances in quantifying air-sea gas exchange 
and environmental forcing, Annu. Rev. Mar. Sci., 1, 213-244, 2009.

Wentz, F. J.: A model function for ocean microwave brightness temperatures, J. Geophys. Res., 88, 1892-1908, 1983.

Wentz, F. J.: A well-calibrated ocean algorithm for special sensor microwave/imager, J. Geophys. Res., 102, 8703-8718, 1997.

Woolf, D. K.: Bubbles and their role in gas exchange, in: The Sea Surface and Global Change, edited by: Liss, P. S. and Duce, R. A., Cambridge Univ. Press, New York, 173-205, 1997.
Wu, J.: Variations of whitecap coverage with wind stress and water temperature, J. Phys. Oceanogr., 18, 1448-1453, 1988.

Zhao, D. and Toba, Y.: Dependence of whitecap coverage on wind and wind-wave properties, J. Oceanogr., 57, 603-616, 2001. 